\title{
Protein acetylation and deacetylation: An important regulatory modification in gene transcription (Review)
}

\author{
CAN XIA ${ }^{1}$, YU TAO ${ }^{1}$, MINGSHAN LI ${ }^{1}$, TUANJIE CHE ${ }^{2}$ and JING QU ${ }^{1}$ \\ ${ }^{1}$ Department of Cell Biology, Medical College of Soochow University, Suzhou, Jiangsu 215123; \\ ${ }^{2}$ Laboratory of Precision Medicine and Translational Medicine, Suzhou Hospital Affiliated to Nanjing Medical University, \\ Suzhou Science and Technology Town Hospital, Suzhou, Jiangsu 215153, P.R. China
}

Received September 8, 2019; Accepted April 24, 2020

DOI: $10.3892 /$ etm.2020.9073

\begin{abstract}
Cells primarily rely on proteins to perform the majority of their physiological functions, and the function of proteins is regulated by post-translational modifications (PTMs). The acetylation of proteins is a dynamic and highly specific PTM, which has an important influence on the functions of proteins, such as gene transcription and signal transduction. The acetylation of proteins is primarily dependent on lysine acetyltransferases and lysine deacetylases. In recent years, due to the widespread use of mass spectrometry and the emergence of new technologies, such as protein chips, studies on protein acetylation have been further developed. Compared with histone acetylation, acetylation of non-histone proteins has gradually become the focus of research due to its important regulatory mechanisms and wide range of applications. The discovery of specific protein acetylation sites using bioinformatic tools can greatly aid the understanding of the underlying mechanisms of protein acetylation involved in related physiological and pathological processes.
\end{abstract}

\section{Contents}

1. Introduction

2. Discovery and concepts of protein acetylation and deacetylation

3. Diseases and protein acetylation and deacetylation

4. Protein acetylation and deacetylation in stem cells

5. Tools to predict acetylation sites

6. Conclusions and prospects

Correspondence to: Dr Jing Qu, Department of Cell Biology, Medical College of Soochow University, 199 Ren Ai Road, Suzhou Industrial Park, Suzhou, Jiangsu 215123, P.R. China

E-mail: qujing@suda.edu.cn

Key words: acetylation, deacetylation, lysine acetyltransferase, lysine deacetylases, non-histone protein acetylation

\section{Introduction}

The functions of biological systems are complicated and diverse, and are largely dependent on the regulation of protein function. After translation is complete, the proteins need to undergo different degrees of chemical modifications, known as post-translational modifications (PTMs), which can change structures by altering the physicochemical properties of the primary sequences and adjusting protein compactness by changing their charge (1). In addition, PTMs can interfere with the shift of protein state (2). The main types of PTM include methylation, acetylation, glycosylation, ubiquitination and phosphorylation (3). Enzymatic acetylation modifies $\sim 50 \%$ of yeast proteins and up to $90 \%$ of higher eukaryotic proteins (4). Fewer acetylated proteins have been identified in prokaryotes (5). The main mechanism of protein acetylation, which is one of the most advanced topics in PTM studies, is that acetyl donors (such as acetyl-CoA) transfer acetyl groups to the proteins under the catalysis of acetyltransferase (6). Acetylation occurs mainly on lysine and can be divided into histone acetylation and non-histone protein acetylation (7). There are currently three well-known forms of acetylation: $\mathrm{N} \alpha$-acetylation, $\mathrm{N} \varepsilon$-acetylation and $\mathrm{O}$-acetylation (8). $\mathrm{N} \alpha$-acetylation refers to the addition of an acetyl group to the $\alpha$-amino group of the $\mathrm{N}$-terminal amino acid, which is an irreversible process; $85 \%$ of human protein is modified by $\mathrm{N} \alpha$-acetylation (9). $\mathrm{N} \varepsilon$-acetylation refers to the addition of an acetyl group to the $\varepsilon$-amino group of the lysine residue, which is a reversible process (10). O-acetylation refers to the addition of an acetyl group to the tyrosine/serine/threonine hydroxyl group (11).

The research history of protein acetylation has spanned $>50$ years. Lysine acetylation in histones was first discovered and proposed by Vincent Allfrey in 1964 (12), which was considered to be related to the regulation of gene transcription (13). Histones contain a large number of two basic amino acids, lysine and arginine, and therefore have a positive charge. If lysine is acetylated, it will no longer be positively charged, so the binding of DNA to the histone is relaxed, which facilitates gene transcription (12). In 2009, $>1,000$ types of acetylated non-histone proteins were historically discovered by studying metabolic pathways of different species (14). In accordance with the large amount of non-histone protein acetylation, 
histone acetyltransferases (HATs) and histone deacetylases (HDACs) were renamed to lysine acetyltransferases (KATs) and lysine deacetylases (KDACs), respectively $(15,16)$. It was discovered that acetylation could affect the enzyme activity of nucleases, thereby regulating the level of substrate RNA (17). This discovery indicates that organisms can achieve self-regulation of cells through nucleases.

It has been reported that there is a wide range of protein acetylation, which could mean that they have crucial physiological functions in various biological activities. Protein acetylation is one of the major regulators of gene transcription (18). Most HATs are localized in the nucleus and function as transcriptional co-activators (19). Acetylation involves the regulation of $>100$ non-histone proteins, including transcription factors (TFs), transcriptional coactivators and nuclear receptors (20). Protein acetylation is also associated with protein degradation. Early studies demonstrated that proteins with free $\alpha$-amino groups can be degraded by ATP-dependent ubiquitin degradation, and that ubiquitin-mediated protein degradation can be prevented when the $\mathrm{N}$-terminal $\alpha$-amino group is acetylated (21). Besides, protein acetylation can regulate a variety of signaling pathways and affect the cell cycle. In this review, the latest advances in protein acetylation of both histone and non-histone proteins will be presented, and the interaction between diseases and protein acetylation will be discussed.

\section{Discovery and concepts of protein acetylation and deacetylation}

Classification of acetyltransferase and deacetylase. Acetylation is catalyzed by KATs, which are distributed in both the nucleus and the cytoplasm. Previous studies have identified $>20$ types of KATs, they can be primarily divided into five groups on the basis of their similarity in several homology regions and acetylation-related motifs: i) General control of amino acid synthesis protein 5 (GCN5) family, including GCN5 (KAT2A), p300/CBP-associated factor (PCAF; KAT2B), histone acetyltransferase 1 (HAT1), elongator acetyltransferase complex subunit 3 , histone acetyltransferase HPA2 (HPA2) and HPA3, which is currently the most typical family of KATs (22-25). ii) MYST family, primarily including $60 \mathrm{kDa}$ tat-protein (KAT5), monocytic leukemia zinc finger protein (KAT6A), MOZ-related factor (KAT6B), histone acetyltransferase binding to ORC1 (KAT7), ortholog of Drosophila males-absent on the first protein (MOF; KAT8), histone acetyltransferase SAS2 (SAS2), SAS3 and ESA1. The classification of this family is due to the presence of the highly conserved MYST domain that consists of an acetyl-CoA binding motif and a zinc finger. According to additional structural features, members of this family can be classified (26-29). iii) p300/cAMP response element-binding protein (CBP or CREB) family (KAT3A/KAT3B), which is closely related to cell differentiation and apoptosis, and has $>75$ non-histone substrates. Members of this family have four separate trans-activation domains, including the cysteine-histidine-rich region 1, the CREB-interacting kinase-inducible domain interacting domain, another cysteine-histidine-rich region and the nuclear receptor co-activator binding domain. p300/CBP is also a coactivator of various TFs, and it can link chromatin remodeling and transcriptional processes to coordinate physiological activities, such as signal transduction, in vivo (30). iv) Transcription initiation factor TFIID $230 / 250 \mathrm{kDa}$ subunit (TAFII230/250) family. This family in humans is TAFII250, and it is a component of the TF complex TAFIID (31). v) Others, including $\alpha$-tubulin $\mathrm{N}$-acetyltransferase 1 , establishment of sister chromatid cohesion $\mathrm{N}$-acetyltransferase (ESCO)1, ESCO2 and HAT1, among which ESCO1 and $\mathrm{ESCO} 2$ are two N-acetyltransferases. Different types of KATs play different roles in cells, and stable expression of various KATs is vital for maintaining the physiological activities of cells (Table I) (23-25,27-29,32-47).

Previous research has demonstrated that KDACs can be primarily divided into four categories (48). Class I includes HDAC1, HDAC2, HDAC3 and HDAC8, which can be found in the nucleus (49). Class II can be found in both the nucleus and the cytoplasm. According to the different catalytic sites, it can be further divided into class IIA and class IIB. Class IIA, including HDAC4, HDAC5, HDAC7 and HDAC9, have a catalytic site and they can perform nuclear transport under cell signal stimulation. Class IIB, including HDAC6 and HDAC10, have two catalytic sites and they are mainly located in the cytoplasm (49). Both class I and class II are zinc-dependent enzymes. Class III, including sirtuin 1-7 (SIRT1-7), are $\mathrm{NAD}^{+}$-dependent enzymes. This class of enzymes have a wide range of subcellular localization (49). Class IV includes only one member, HDAC11, which is a zinc-dependent enzyme. HDAC11 mediates deacetylation of lysine on the $\mathrm{N}$-terminal tail of the core histones (50). In addition to these four categories, $\mathrm{T}$ cell transcription factor 1 and lymphoid enhancer-binding factor 1 are also two KDACs located in the nucleus (Table II) (51-70). Typically, acetyltransferases and deacetylases work together to regulate lysine acetylation and other various physiological processes in the organism. If the balance of acetylation and deacetylation becomes dysregulated, it is likely to cause tumor growth and a number of non-neoplastic diseases such as inflammatory diseases and neurological disorders (71).

Histone acetylation and deacetylation. The study of protein acetylation began with histones. Chen et al (72) reported that the degree of acetylation at H4K16 was notably decreased in prematurely aging mice compared with normal mice. Moreover, the expression of MOF, which is the related KAT, was greatly reduced. The symptoms of premature aging can be improved by increasing the degree of acetylation of H4K16 or increasing the expression of MOF in a variety of ways. Michishita et al (73) revealed that SIRT6, which is primarily localized in the nucleus, is also involved in senescence. SIRT6 specifically binds to the chromatin telomere region and is capable of acetylating H3K9 and H3K56 in the way of Ne-acetylation. Blocking SIRT6 can lead to telomere dysfunction and chromatin terminal fusion. These ultimately result in cell senescence, and produce a symptom similar to Werner syndrome. Taken together, these studies suggest that histone acetylation or deacetylation is closely related to aging.

It has been reported that combinations of monomethylation of histone $\mathrm{H} 3$ at lysine $4(\mathrm{H} 3 \mathrm{~K} 4 \mathrm{mel})$ and histone 3 lysine 27 acetylation (H3K27ac) or H3K27me3 are often used as a basis to differentiate active enhancers from inactive enhancers and 
Table I. Published data of KATs.

\begin{tabular}{|c|c|c|c|c|c|}
\hline Author, year & KAT family & Members & Localization & Substrate & (Refs.) \\
\hline Fournier et al, 2016 & GNAT & GCN5 (KAT2A) & Nucleus & PLK4 and TBX5 & (34) \\
\hline Ghosh et al, 2018 & & PCAF (KAT2B) & & & (36) \\
\hline Ruiz-Garcia et al, 1998 & & HAT1 & $\begin{array}{l}\text { Cytoplasm/ } \\
\text { nucleus }\end{array}$ & Histone & (23) \\
\hline Miskiewicz et al, 2011 & & ELP3 & $\begin{array}{l}\text { Cytoplasm/ } \\
\text { nucleus }\end{array}$ & Brunchpilot & (24) \\
\hline \multirow[t]{2}{*}{ Sampath et al, 2013} & & HPA2 & Cytoplasm & $\begin{array}{l}\text { Histone/Polyamines/ } \\
\text { Small basic proteins }\end{array}$ & $(25)$ \\
\hline & & HPA3 & Cytoplasm & $\begin{array}{l}\text { Histone/Polyamines/ } \\
\text { D-amino acids }\end{array}$ & \\
\hline Bao et al, 2018 & MYST & & & & $(35)$ \\
\hline Cheng et al, 2019 & & Tip60 (KAT5) & Nucleus & Ran and Pacer & (37) \\
\hline Rokudai et al, 2013 & & MOZ (KAT6A) & Nucleus & p53 & (33) \\
\hline Pelletier et al, 2002 & & MORF (KAT6B) & Nucleus & Runx2 & (32) \\
\hline Miotto et al, 2002 & & HBO1 (KAT7) & Nucleus & CDT1 & (38) \\
\hline Yuan et al, 2012 & & MOF (KAT8) & Nucleus & Histone & (39) \\
\hline Reiter et al, 2015 & & SAS2 & Nucleus & Histone & (27) \\
\hline Church et al, 2017 & & SAS3 & Nucleus & Histone & (28) \\
\hline Yan et al, 2000 & & ESA1 & Nucleus & Histone & (29) \\
\hline Chang et al, 2017 & p300/CBP & p300 (KAT3B) & Nucleus & Snail/Smad4/PCNA/ & $(40)$ \\
\hline Yang et al, 2015 & & & & FoxO1 & $(41)$ \\
\hline Cazzalini et al, 2014 & & & & & $(42)$ \\
\hline Senf et al, 2011 & & CBP (KAT3A) & Nucleus & Snail/FoxO1/PCNA & (43) \\
\hline Lee et al, 2018 & TAFII230/250 & TAFII 250 & Nucleus & Histone & (44) \\
\hline Nakakura et al, 2016 & Others & ATAT1 & Cytoplasm & $\alpha$-tubulin & $(45)$ \\
\hline Zhang et al, 2008 & & $\begin{array}{l}\text { ESCO1 } \\
\text { ESCO2 }\end{array}$ & $\begin{array}{l}\text { Nucleus } \\
\text { Nucleus }\end{array}$ & SMC3 & (46) \\
\hline Wu et al, 2012 & & HAT1 (KAT1) & Nucleus & Histone & (47) \\
\hline
\end{tabular}

GNAT, GCN5-related N-acetyltransferases family; GCN5, general control of amino acid synthesis protein 5; PCAF,p300/CBP-associated factor; Tip60, 60 kDa tat-interactive protein; MOZ, monocytic leukemia zinc finger protein; MORF, MOZ-related factor; HBO1, histone acetyltransferase binding to ORC1; MOF, ortholog of Drosophila males-absent on the first; CBP, CREB-binding protein; TAFII250, transcription initiation factor TFIID $250 \mathrm{kDa}$ subunit; ATAT1, $\alpha$-tubulin N-acetyltransferase 1; PLK4, polo-like kinase 4; TBX5, T-box protein 5; Runx2, runt-related transcription factor 2; CDT1, chromatin licensing and DNA replication factor 1; PCNA, proliferating cell nuclear antigen; ESCO, establishment of sister chromatid cohesion N-acetyltransferase; HAT1, histone acetyltransferase 1; Ran, ras-related nuclear protein; Snail, zinc finger protein SNAI1; FoxO1, forkhead box protein O1; SMC3, structural maintenance of chromosomes 3; ELP3, elongator complex protein 3; HPA2, histone acetyltransferase HPA2; SAS2, histone acetyltransferase SAS2; ESA1, Histone acetyltransferase ESA1.

poised enhancers $(74,75)$. However, this method of identification does not completely distinguish between other types of enhancers, such as super-enhancer (76). It has been found that $\mathrm{H} 3 \mathrm{~K} 122 \mathrm{ac}$ is also enriched with $\mathrm{H} 3 \mathrm{~K} 27 \mathrm{ac}$ on the active enhancer. H3K122ac can be used as a marker to identify some novel enhancers, but some of these novel enhancers will also be enriched in $\mathrm{H} 3 \mathrm{~K} 27 \mathrm{ac}$. This characteristic provides new ideas for comprehensive identification enhancers (77). Histone acetylation also plays a role in the repair of DNA replication forks. Nucleosome acetyltransferase of $\mathrm{H} 4(\mathrm{NuA} 4)$ is involved in acetylation of $\mathrm{H} 4$ on four lysine residues at position 5, 8, 12 and 16, which is $\mathrm{Ne}$-acetylation. This modification changes the structure of chromatin, facilitating the repair of broken DNA replication forks (78). SWI1 promotes histone $\mathrm{H} 4$ acetylation by stabilizing the expression of $\mathrm{NuA} 4$. Loss of SWI1 leads to the instability of chromatin modification-related protein vid21, a regulatory subunit of $\mathrm{NuA} 4$, leading to a reduction in histone $\mathrm{H} 4$ acetylation (79). It is reported that the level of H3K56ac increases from low to high cell density and H3K56ac was observed to increase when lactic acid levels rose. This phenomenon may be attributed to changes in the levels of SIRT6. Furthermore, the level of H3K56ac was increased in cells with 
Table II. Published data of KDACs.

\begin{tabular}{|c|c|c|c|c|c|}
\hline Author, year & Classes & Members & Localization & Functions & (Refs.) \\
\hline Muller et al, 2013 & Class I & HDAC1 & Nucleus & Mediates deacetylation of lysine & $(51,52)$ \\
\hline \multirow[t]{2}{*}{ Miller et al, 2010} & & HDAC2 & Nucleus & residues on the $\mathrm{N}$-terminal part of & \\
\hline & & HDAC3 & Nucleus & the core histones and plays an & \\
\hline Saito et al, 2019 & & HDAC8 & Nucleus & $\begin{array}{l}\text { important role in transcriptional } \\
\text { regulation, cell cycle progression } \\
\text { and developmental events. }\end{array}$ & (53) \\
\hline Winbanks et al, 2011 & Class II & HDAC4 & Nucleus & & $(54)$ \\
\hline Cho et al, 2013 & Class IIA & HDAC5 & Nucleus & & $(55)$ \\
\hline Bradley et al, 2015 & & HDAC7 & Nucleus & & $(56)$ \\
\hline Hu et al, 2019 & & HDAC9 & Nucleus & & $(57)$ \\
\hline Bitler et al, 2017 & Class IIB & HDAC6 & Cytoplasm & & $(58)$ \\
\hline Radhakrishnan et al, 2015 & & HDAC10 & Cytoplasm & Involved in MSH2 deacetylation & $(59)$ \\
\hline Zerr et al, 2016 & Class III & SIRT1 & Nucleus & Deacetylates TGF- $\beta$ & $(60)$ \\
\hline Yuan et al, 2015 & & SIRT2 & Cytoplasm & Deacetylates $\alpha$-tubulin & $(61)$ \\
\hline Ahn et al, 2008 & & SIRT3 & Mitochondria & Regulates tissue-specific ATP levels & $(62)$ \\
\hline Jeong et al, 2013 & & SIRT4 & Mitochondria & $\begin{array}{l}\text { Regulates the cellular metabolic } \\
\text { response to DNA damage }\end{array}$ & $(63)$ \\
\hline Rardin et al, 2013 & & SIRT5 & Mitochondria & $\begin{array}{l}\text { Regulates the mitochondrial } \\
\text { lysine succinylome and metabolic } \\
\text { networks }\end{array}$ & (64) \\
\hline Kaluski et al, 2017 & & SIRT6 & Nucleus & Involved in energy metabolism & $(65)$ \\
\hline Barber et al, 2012 & & SIRT7 & Nucleolus & $\begin{array}{l}\text { Mediates deacetylation of } \\
\text { H3K18ac }\end{array}$ & (66) \\
\hline Yuan et al, 2018 & Class IV & HDAC11 & Nucleus & $\begin{array}{l}\text { Mediates deacetylation of lysine } \\
\text { residues on the N-terminal } \\
\text { part of the core histones. Plays an } \\
\text { important role in transcriptional } \\
\text { regulation, cell cycle progression } \\
\text { and developmental events. }\end{array}$ & (67) \\
\hline Chatterjee et al, 2015 & Others & TCF1 & Nucleus & $\begin{array}{l}\text { Mediates differentiation of } \\
\text { embryonic stem cells }\end{array}$ & (69) \\
\hline Abu-Elmagd et al, 2010 & & LEF1 & Nucleus & $\begin{array}{l}\text { Participates in the Wnt signaling } \\
\text { pathway. }\end{array}$ & (70) \\
\hline
\end{tabular}

TCF1, T cell transcription factor 1; LEF1, lymphoid enhancer-binding factor 1; MSH2, human mutS homolog 2; TGF- $\beta$, transforming growth factor- $\beta$; HDAC, histone deacetylase; SIRT, sirtuin; ac, acetylation.

low acetylation immediately after DNA damage, and the level was decreased in cells with high acetylation immediately after DNA damage, which indicates the association between acetylation and repair after DNA damage (80). Moreover, histone acetyltransferase Gcn5p is a catalytic subunit of a nuclear HAT. Gcn5p catalyzes the acetylation of histone $\mathrm{H} 3$ and $\mathrm{H} 4$ at specific lysines, which is $\mathrm{N}-\varepsilon$ acetylation at specific lysines in the amino-terminal domains, promoting cell growth. These results suggest that the acetylation of specific lysines at $\mathrm{H} 3$ and $\mathrm{H} 4$ is essential for normal cell cycle progression (81). Oridonin is a tetracycline diterpenoid compound that is an important traditional Chinese herb. It has been reported that oridonin inhibits tumor cell proliferation and induces apoptosis, possibly by inducing the hyperacetylation of histone $\mathrm{H} 3$ (82).

Non-histone protein acetylation and deacetylation. As studies of histone acetylation have gradually deepened, researchers proposed the idea that non-histone proteins, such as p53, could also be acetylated. Although non-histone protein acetylation has been studied for a shorter period of time compared with histone acetylation, non-histone protein acetylation has been highlighted recently due to its extensive regulatory functions. 
There are numerous types of non-histone proteins that can be acetylated, among which TFs are the main members (83). These non-histone proteins are widely involved in a variety of physiological processes in different ways, including gene transcription and protein folding (71).

As a tumor suppressor, p53 actively participates in the regulation of tumor formation and can be acetylated by the p300/CBP family in the way of Ne-acetylation. The p300/CBP family can acetylate the C-terminal lysine of p53 and further activate specific DNA binding sites on p53 (84). When DNA is damaged, p300/CBP family members binds to the promoter of p53 to increase the transcriptional activity of its gene in order to enhance p53 stability (85). p300/CBP not only regulates p53 activity in cells by acetylating p53, but also causes the inactivation of E3 ubiquitin-protein ligase murine double minute 2 (MDM2) to regulate p53. MDM2 also inhibits p300/CBP-mediated p53 acetylation, and p53 can be effectively degraded by MDM2 after being deacetylated (86). p53 acetylation is also associated with the regulation of apoptosis. p300 is a key TF that promotes cell transformation from $G_{1}$ to $S$ phase and regulates p53 transcriptional activity via acetylation $(87,88)$. It has been demonstrated that DEAD-box RNA helicase 24 (DDX24) interacts with p300 to inhibit p300-mediated p53 acetylation. When DDX24 was knocked out in human lung cancer cells, it was found that the level of p53 acetylation was significantly increased, and $\mathrm{G}_{1} / \mathrm{S}$ arrest was observed in these cells. Following which, cells showed apoptosis (88). Inhibitor of DNA binding 4 is a differentiation inhibitory protein that promotes p53-dependent apoptosis by increasing the level of p53 acetylation (89). Moreover, it has been reported that the acetylation of p53 is associated with aging (90). Transcriptional coactivator with a PDZ-binding motif (TAZ) inhibits p300-mediated p53 acetylation by suppressing the binding of p53 and p300 (91). Furthermore, experiments have revealed that TAZ-knockout causes p53-dependent cellular senescence in normal human fibroblasts, which may contribute to tumorigenesis by suppressing p53-mediated cellular senescence (91). The association of p53 acetylation with apoptosis and senescence suggests that p53 is related to cancer (92). Overexpression of HDAC2 is found in a variety of cancer cells, such as breast cancer and gastric cancer cells $(93,94)$. HDAC2 causes the deacetylation of the C-terminal lysine on $\mathrm{p} 53$, and functions as a corepressor involved in the regulation of target genes. If KDAC inhibitors (KDACIs) are used to keep some key lysine residues highly acetylated on p53, the stability of p53 can be enhanced (95). KDACIs also inhibit HDAC6 and promote the degradation of mutant p53 via MDM2 and CHIP ligase, which is hypothesized to be a mechanism for eliminating mutant p53 (96). Iron overload and fluoride may also be associated with p53 acetylation. Some studies have demonstrated that iron overload in macrophages may promote the production of reactive oxygen species, increase p53 acetyltransferase activity, and ultimately lead to macrophage M1 polarization by inducing the expression and acetylation of p53 (97,98). Fluoride can induce the acetylation of K379 on p53, which can be recovered by SIRT1 $(85,99)$. Further study has indicated that SIRT1 deacetylates fluoride-induced p53 acetylation to attenuate fluorescence-induced cell growth inhibition, mitochondrial damage, DNA damage and apoptosis (85). As one of the typical representatives of non-histone protein acetylation, p53 acetylation broadens the scope of acetylation modification, providing an important basis for further studies on protein acetylation.

Signal transducer and activator of transcription 3 (STAT3) serves a dual role in transmitting signals and initiating gene transcription (100). The nuclear receptor Nur77 can recruit $\mathrm{p} 300$ and reduce HDAC1 expression, which promotes STAT3 acetylation in the way of $\mathrm{N} \varepsilon$-acetylation and enhance the transcriptional activity of STAT3 (101). Decreased transcriptional capacity of STAT3-dependent genes can be reversed using KDACI trichostatin A or ITF2357 to inhibit acetylation of STAT1 or STAT3. This may be useful in the treatment of chronic mucocutaneous candidiasis (102). In the nucleus, lysyl oxidase like 3 associates with STAT3 to deacetylate and deacetyliminate STAT3 on multiple acetyl-lysine sites. As the result of this, STAT3 dimerization is disrupted and STAT3 transcription activity is inhibited (103). The acetylation of K685 on STAT3 can be regulated by $\mathrm{p} 300 / \mathrm{CBP}$, which enhances sequence-specific DNA binding ability and transcriptional activity of STAT3. Microglia are the innate immune cells of the central nervous system, which can inhibit the toxic toxic accumulation of $\beta$-amyloid. However, activated microglia can engulf synapses and activate inflammatory cytokines, causing the loss of synapses and the damage of neurons (104). It is reported that the activation of microglia is related to the deposition of amyloid protein (105). The synthetic form of $\mathrm{A} \beta$ peptides was used to treat primary and immortalized microglial cells, and then the relative abundance of acetylated and phosphorylated STAT3 was measured at different stages. In the early stage, the level of STAT3 acetylation on K685 was increased. Then, in the delayed one, its isoform will be phosphorylated on Y705 residue (106). Although the association between acetylation and phosphorylation is still unknown in this event, the acetylation of STAT3 is associated with the nervous system (106). Studies have also found that acetylation and deacetylation of STAT3 can regulate the tricarboxylic acid cycle $(107,108)$. Serum starvation and reintroduction or insulin stimulation can induce STAT3 CBP acetylation in serum starved cells and result in the transfer of STAT3 into mitochondria (107). If STAT3 is deacetylated by SIRT5, STAT3 will reduce the association with the pyruvate dehydrogenase complex E1 and slow the conversion of pyruvate to acetyl-CoA (107).

Transcription factor EB (TFEB), a primary TF for autophagy and lysosome-related gene expression, can be acetylated by GCN 5 at K 274 and $\mathrm{K} 279$ in the way of $\mathrm{Ne}$-acetylation, which inhibits the binding of TFEB to promoters of its target genes chloride voltage-gated channel 7, galactosidase $\alpha$ and cathepsin D by interfering with TFEB dimerization (109). Interfered TFEB dimerization results in a decreased binding affinity to DNA, which inhibits its transcriptional activity and ultimately suppresses the biogenesis of lysosomes and aggregation of autophagosomes (Fig. 1) (109). NAD ${ }^{+}$-dependent deacetylase SIRT1 deacetylates TFEB at K116, enhancing lysosomal function by upregulating transcriptional levels of TFEB downstream targets (110). HDAC inhibitor suberoylanilide hydroxamic acid (SAHA) upregulates TFEB acetylation by recruiting increased levels of acetyl-Coenzyme A acetyltransferase 1 to TFEB; the acetylation sites on TFEB induced 


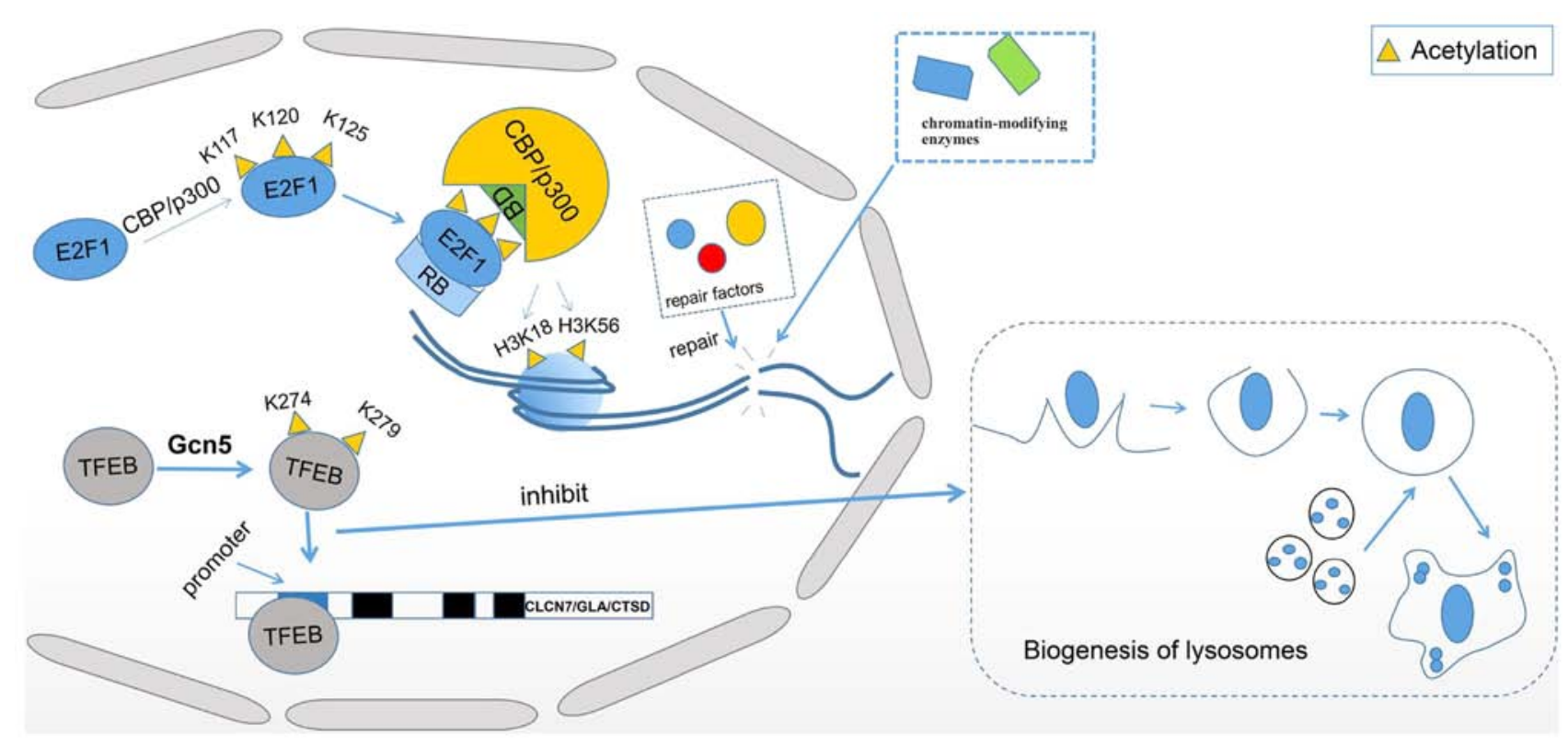

Figure 1. Biological processes regulated by acetyltransferase GCN5 and p300/CBP. GCN5 acetylates TFEB at K274 and K279, hindering the binding of TFEB to its target gene promoters CLCN7, GLA and CTSD. This process inhibits the biogenesis of lysosomes and aggregation of autophagosomes. In addition, the acetylation of $\mathrm{E} 2 \mathrm{~F} 1$ at $\mathrm{K} 117, \mathrm{~K} 120$ and $\mathrm{K} 125$ by acetyltransferase $\mathrm{p} 300 / \mathrm{CBP}$ creates a binding motif at the BD of the p300/CBP protein to attract more p300/CBP with the help of RB tumor-suppressor protein. Subsequently, the recruitment of p300/CBP induces the acetylation of H3K18 and H3K56, and then facilitates the binding of chromatin-modifying enzymes and repair factors for DNA double-strand breaks. GCN5, general control of amino acid synthesis protein 5; CBP, CREB-binding protein; TFEB, transcription factor EB; CLCN7, chloride voltage-gated channel 7; GLA, galactosidase $\alpha$; CTSD, cathepsin D; E2F1, E2F transcription factor 1; BD, bromodomains; RB, retinoblastoma.

by SAHA are K91, K103, K116 and K430 (111). It has been reported that SIRT1 deacetylates TFEB at lysine residue 116 and the deacetylation of TFEB in microglia induces the regulatory ability of microglia to degrade fibrillar $A \beta$, the deacetylation process further reduces the number of deposited amyloid plaques by facilitating lysosomal biogenesis, which could be helpful in the treatment of Alzheimer's disease (110). In human diabetic kidney disease, deacetylation of TFEB by HDAC6 has been observed, which promotes its activation (112). Tubastatin A, an inhibitor of HDAC6, increases the acetylation level of TFEB accordingly (113). In addition, experiments have demonstrated that the use of tubastatin A can attenuate renal injury, which indicates that TFEB may be a promising target for renal diseases treatment (112). Recently, it has been demonstrated that acetylation of E2F transcription factor 1 (E2F1) is associated with the repair of DNA double-strand breaks (DSBs). The acetylation of E2F1 at K117, K120 and K125 by acetyltransferase $\mathrm{p} 300 / \mathrm{CBP}$ creates a binding motif for the bromodomains of $\mathrm{p} 300 / \mathrm{CBP}$, which results in the recruitment of $\mathrm{p} 300 / \mathrm{CBP}$ to DSBs with the help of retinoblastoma tumor-suppressor protein, an important regulator of E2F1. Subsequently, p300/CBP acetylates H3K18 and H3K56, and then facilitates the recruitment of chromatin-modifying enzymes and repair factors for DSBs (Fig. 1) (114). GCN5 catalyzes the histone acetylation at the promoter regions of E2F1, enhancing the transcription of target genes cyclin DI and cyclin El. The expression of GCN5 promotes cell growth and the G1/S phase transition in lung cancer cells, which is aided by E2F1 to control the transcription of cyclin E1 and cyclin D1. These data suggest that the interaction between GCN5 and E2F1 may be a potential target for lung cancer treatment (115).
Zinc finger protein SNAI1 (Snail) is involved in the induction of epithelial-mesenchymal transition (EMT) and plays a crucial role in the metastasis of malignant tumors (116). The Snail protein is usually comprised of a C-terminal zinc finger domain and an $\mathrm{N}$-terminal SNAG domain. The C-terminal zinc finger domain recognizes the E-box sequence in the promoter region of E-cadherin. The SNAG domain associates with $\mathrm{HDAC} 1 / 2$ and corepressor $\mathrm{mSin} 3 \mathrm{~A}$, and then recruits the repressor complex to E-cadherin promoter, here HDAC1/2 deacetylates histone $\mathrm{H} 3$ and $\mathrm{H} 4$, inhibiting the expression of E-cadherin (Fig. 2) (117). In previous years, numerous studies have reported that there are lysine acetylation sites on Snail and Snail acetylation activates the expression of Snail gene $(40,118)$. It has been demonstrated that the interaction of CBP and Snail can cause the acetylation of K146 and K187 on Snail in the way of Ne-acetylation. Snail can be used as a transcriptional activator to induce the expression of cytokines in the tumor microenvironment during tumor metastasis, or as a transcriptional repressor to inhibit the expression of E-cadherin during tumor metastasis (118). Cancer cells containing acetylated Snail have increased metastatic ability compared with primary cancer cells $(116,118)$. In addition, it has been found that Snail binds to the E-box motif on the E-cadherin promoter and recruits HDACs to suppress the expression of E-cadherin. In lung cancer cells, if recombinant Snail and p300 are incubated with acetyl-CoA, acetylation of Snail will be observed (40). In addition to CBP and p300, KDACIs can also promote the expression of Snail and induce EMT in hepatoma cells. One of the possible reasons is that KDACIs regulate the stability of Snail by upregulating the expression of COP9 signalosome 2 (CSN2). CSN2 binds to Snail and exposes its acetylation site, which then promotes the acetylation of Snail. Therefore, 


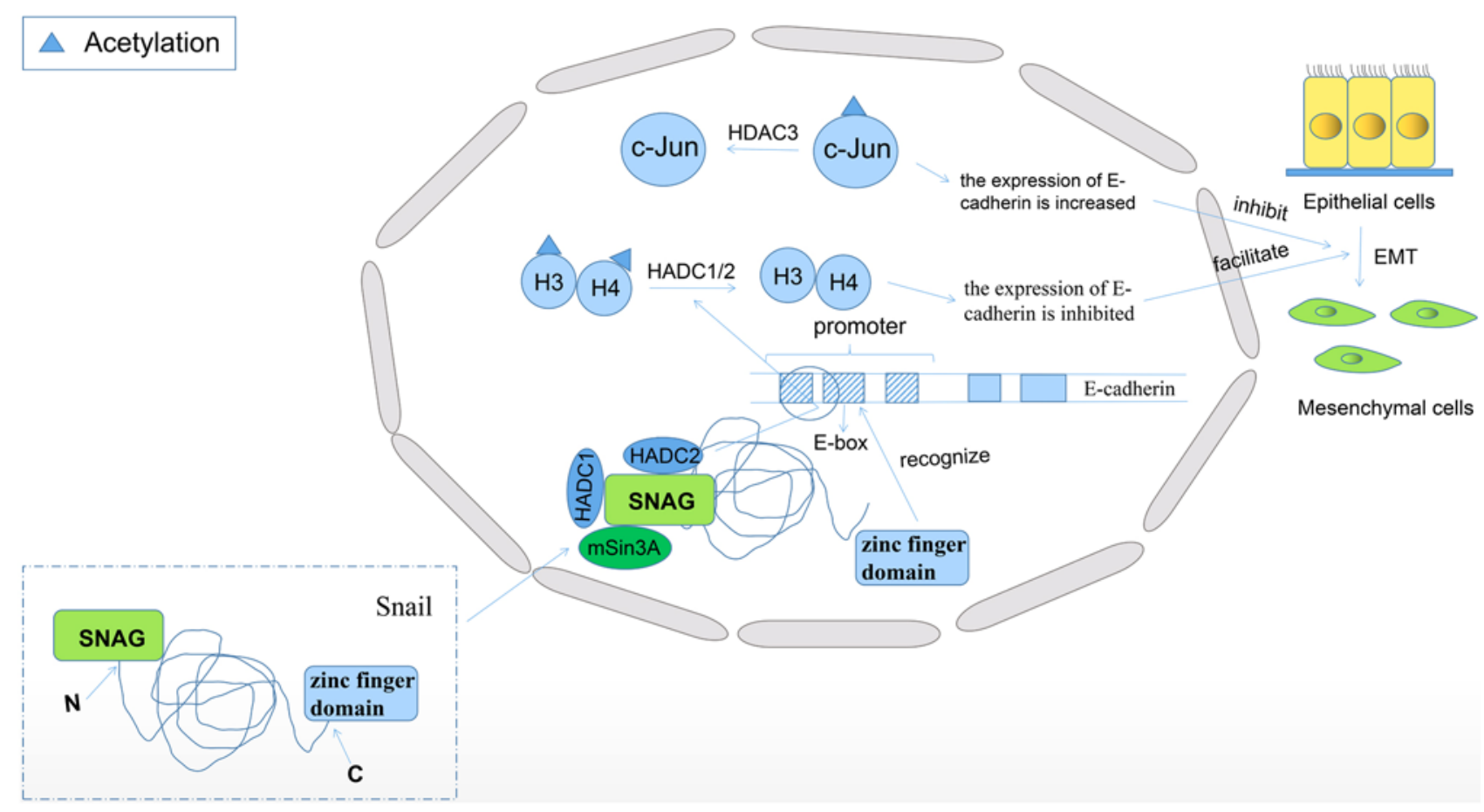

Figure 2. Acetylation and deacetylation associated with EMT. Snail, a zinc finger protein, comprises a C-terminal zinc finger domain and an N-terminal SNAG domain. The C-terminal zinc finger domain recognizes the E-box sequence in the promoter region of E-cadherin. The SNAG domain associates with $\mathrm{HDACl} / 2$ and corepressor mSin3A, and then recruits the repressor complex to the E-cadherin promoter, where HDAC1/2 deacetylate histone $\mathrm{H} 3$ and $\mathrm{H} 4$, inhibiting the expression of E-cadherin and promoting the process of EMT. Human c-Jun is a transcriptional regulator of JUN proto-oncogene. It is reported that the downregulation of HDAC 3 expression can increase the acetylation of c-Jun and may lead to the degradation of c-Jun, which ultimately increases the expression of E-cadherin and decreases the expression of snail, thus inhibiting the process of EMT. EMT, epithelial-mesenchymal transition; Snail, zinc finger protein SNAI1; HDAC, histone deacetylase.

its phosphorylation and ubiquitination are inhibited and its degradation is inhibited (119). Human c-Jun is a transcriptional regulator of JUN proto-oncogene, and c-Jun N-terminal kinase gene is associated with the expression of E-cadherin and snail. It has been reported that the downregulation of HDAC3 expression can increase the acetylation of c-Jun and may lead to the degradation of c-Jun, which ultimately increases the expression of E-cadherin and decreases the expression of snail, thus inhibiting the process of EMT (Fig. 2) (120). Due to the promotion of tumor metastasis by acetylated Snail, Snail could become an effective target for cancer therapy.

Myc is involved in the development of tumors and the induction of apoptosis (121). As reported, KAT2A interacts closely with Myc. KAT2A can acetylate K323 on Myc to maintain its stability in the way of $\mathrm{Ne}$-acetylation, and Myc can recruit KAT2A into the RNA polymerase III template to facilitate the transcription of the Myc target gene (122). Besides acetylation, SIRT1 deacetylates c-Myc and promotes its binding to Max, which is a partner essential for its activation. This process increases the activity of c-Myc and promotes the proliferation of K562 cells (123). Previous studies that used KDACIs reported an association between Myc acetylation and disease $(124,125)$. For example, the gene expression profiles of normal acute myelocytic leukemia (AML) cell lines were compared with KDACI-treated AML primary blasts, it was found that MYC gene was significantly upregulated. Treatment with KDACI led to a significant decrease in the expression of c-Myc. The process would also activate TNF-related apoptosis-inducing ligand, a member of the tumor necrosis factor family, and cause apoptosis (125).

When an organism is exposed to high temperatures, heat shock protein 90 (Hsp90) is synthesized by thermal excitation to protect the organism, and it has molecular chaperone activity (126). The deacetylation of Hsp90 is effectively regulated by HDAC6. The inactivation of HDAC6 leads to a higher degree of acetylation of Hsp90, which causes Hsp90 to separate from P23 and lose its chaperone activity (127). If K294 on Hsp90 is not normally acetylated, the life cycle of Hsp90 will be shorter and the function will be weakened (128). In breast cancer cells, carbamazepine can inhibit the effect of HDAC6 on Hsp90 and further promote the degradation of HER2 protein (129). This finding is expected to contribute to the development of breast cancer treatment strategies.

Additionally, it has been demonstrated that acetylation at lys1053 of the activation loop of the kinase domain may positively regulate kinase activity of VEGFR-2 (130). Also, KAT7, a member of MYST family, colocalizes with vascular endothelial growth factor receptor 2 (VEGFR-2), directly regulating the chromatin structure of the VEGFR-2 locus and affecting VEGFR-2 transcriptional activity. KAT7 depletion was demonstrated to reduce the expression of VEGFR-2 (131). Also, using KAT7 morpholino inhibitor in zebrafish embryos lead to abnormal vessel formation (131). All these results indicate that KAT7 plays a critical role in endothelial function.

ESCO1 and ESCO2 are two KATs that are involved in the aggregation of sister chromatids in the $S$ phase of the cell cycle. K105 and K106 on human structural maintenance 
Table III. Summary of acetylated proteins.

\begin{tabular}{|c|c|c|c|c|}
\hline Author, year & Protein names & Acetylation site & Functions & (Refs.) \\
\hline Gallinari et al, 2007 & Histone & H3К9 & Affects heart development & $(134)$ \\
\hline Schlesinger et al, 2011 & & H3K14 & Affects heart development & $(135)$ \\
\hline Pradeepa et al, 2017 & & H3K27 & Identification enhancer & $(77)$ \\
\hline Michishita et al, 2008 & & $\mathrm{H} 3 \mathrm{~K} 56$ & Related to cellular aging & $(73)$ \\
\hline Pradeepa et al, 2017 & & H3K 122 & Identification enhancer & $(77)$ \\
\hline Chen et al, 2016 & & H4K16 & Improves premature aging & $(72)$ \\
\hline Leszczynska et al, 2015 & $\mathrm{p} 53$ & $\begin{array}{l}\text { K120 } \\
\text { K164 }\end{array}$ & Regulation of apoptosis & $(136)$ \\
\hline Suzuki et al, 2018 & & & & $(85)$ \\
\hline Shi et al, 2016 & & K305 & Regulate the transcriptional activity of p53 & $(88)$ \\
\hline Marrogi et al, 2001 & & K379 & Related to fluorosis & $(97)$ \\
\hline Shi et al, 2016 & & K382 & Regulate the activity of p53 apoptotic & $(88)$ \\
\hline Eufemi et al, 2015 & STAT3 & K685 & $\begin{array}{l}\text { Enhance sequence-specific DNA binding } \\
\text { ability, transcriptional activity and } \\
\text { transactivation activity }\end{array}$ & $(106)$ \\
\hline Kenneth et al, 2007 & Myc & K323 & Activate TRAIL and cause apoptosis & $(122)$ \\
\hline Meng et al, 2011 & Hsp90 & K294 & Related to the activity and cycle of Hsp90 & $(129)$ \\
\hline Hsu et al, 2014 & Snail & $\begin{array}{l}\text { K146 } \\
\text { K187 }\end{array}$ & Prevents the repressor complex formation & $(118)$ \\
\hline Rowland et al, 2009 & Smc3 & $\begin{array}{l}\text { K105 } \\
\text { K106 }\end{array}$ & Condensation of sister chromatids & $(133)$ \\
\hline Vadvalkar et al, 2017 & MPC2 & $\begin{array}{l}\text { K19 } \\
\text { K26 } \\
\text { K27 } \\
\text { K122 }\end{array}$ & Related to pyruvate transport activity & $(137)$ \\
\hline Hu et al, 2017 & PGK1 & K323 & Related to cancer cell proliferation & $(138)$ \\
\hline
\end{tabular}

STAT3, signal transducer and activator of transcription 3; Hsp90, heat shock protein 90; Snail, zinc finger protein SNAI1; Smc3, structural maintenance of chromosomes 3; MPC2, mitochondrial pyruvate carrier 2; TRAIL, TNF-related apoptosis-inducing ligand; PGK1, phosphoglycerate kinase 1 .

of chromosomes 3 (SMC3) are two conserved amino acid residues that can be acetylated by ESCO1 and ESCO2 (46). If these sites are mutated to non-acetylated, the sister chromatid will lose cohesion and the human genome will be unstable $(46,132)$. Further study revealed that the acetylation of SMC3 altered the function of the N-terminal ATPase of SMC3 and transformed the chromosome-bound cohesin complex into a cohesive complex (133). These results indicate that acetylation of SMC3 regulates the aggregation of sister chromatids and keeps the cell cycle functioning normally. In addition, some of the proteins and acetylation sites involved in this review are listed in Table III $(72,73,77,85,97,106,118,122$, 129,133-138).

Although protein acetylation has been well studied in eukaryotes, new insights into protein acetylation in prokaryotes has gained more attention in recent years. Shewanella baltica is one of the specific spoilage organism of aquatic products and numerous lysine acetylation sites have been detected in its protein, such as key enzymes involved in fat metabolism and putrescine biosynthesis that are related to the spoilage ability of Shewanella baltica (139). Previously, putrescine was demonstrated to have effects on proliferation, migration and apoptosis of human skin fibroblasts (140). Cyanobacteria are the only prokaryotes capable of performing oxygenic photosynthesis. Experimental data have demonstrated that lysine acetylation in cyanobacteria plays an important role in the regulation of photosynthesis (141). Also, acetylation is abundant in Escherichia coli (142).

As mitochondria carry out a number of essential functions in metabolism, the study of Mechanisms and Dynamics of Protein Acetylation in Mitochondria becomes necessary. PCAF functions as a lysine acetyltransferase inside mitochondria (143). PCAF affects intermediary metabolism by acetylating isocitrate dehydrogenase 2 (IDH2) at K180 in the mitochondrial matrix, which interferes with the catalytic mechanisms of isocitrate binding and oxidation (143). A number of central enzymes in mitochondria are deacetylated by SIRT3, which reverses the suppressive effect of acetylation, 
leading to enhanced oxidative metabolism (144). It was proposed that most protein lysine acetylation in mitochondria is due to non-enzymatic modification of protein lysine residues. The environment of the mitochondrial matrix has an alkaline $\mathrm{pH}$ and abundant acetyl-CoA, which increases the number of amino groups acting as nucleophiles towards the inherently reactive acetyl-CoA, resulting in an acetylated lysine (145). Pyruvate is a principal source of acetyl-CoA. The data suggest excessive lysine acetylation in the mitochondrial matrix can be prevented by decreasing the matrix acetyl-CoA formation (146). In the mitochondria, when acetyl-CoA levels exceed physiological requirements, a signal is generated to slow flux through oxidative energy production (144). A substrate-level braking system is established via the induction of acetyl-CoA-dependent protein acetylation. When energy demands require increased oxidative metabolism, SIRT3 expression is induced, which removes the brake and allows the cell to increase energy production (144). Acetylation in mitochondria is primarily the result of nonenzymatic modification of lysine residues, some enzyme-mediated acetylation also exists in mitochondria. PCAF acetylates isocitrate dehydrogenase 2 (IDH2) at lysine 180, which may reduce IDH2 affinity for isocitrate. In this way, PACF influences myoblast differentiation (143). CCAAT/enhancer-binding protein a $(\mathrm{C} / \mathrm{EBP} \alpha)$, which can be acetylated by $\mathrm{p} 300$, regulates the transcription of metabolic genes and further enhances its transactivation activity (147). In addition, $\mathrm{C} / \mathrm{EBP} \alpha$ can be deacetylated by SIRT1 and low acetylation levels of $\mathrm{C} / \mathrm{EBP} \alpha$ enhances mitochondrial function. When energy is required, SIRT1 is activated by high levels of nicotinamide adenine dinucleotide; mitochondrial biogenesis and functions are regulated in this way (147).

\section{Diseases and protein acetylation and deacetylation}

Acute kidney injury (AKI). AKI refers to a rapid decline in renal function in a short period of time and leads to the accumulation of metabolic waste (148). AKI primarily affects renal tubules. Tubular cells are rich in mitochondria, and changes in mitochondria of the tubules are an important indicator of the occurrence and development of renal diseases (149). AKI can be caused by various factors, such as bacterial infection, drugs and sepsis (150). At present, the clinical diagnosis of AKI primarily depends on the detection of elevated serum creatinine levels and decreased urine output (151). It has been demonstrated that the KDACI participates in the process of renal regeneration and repair, and plays different roles in AKI models (152). Differences in cell type and etiology will determine activation of KDACs, thus leading to cell survival or death (153). Using SIRT1, which is currently studied more, as an example, SIRT1 can participate in the regulation of a variety of signaling pathways, and plays a role in anti-oxidative stress and anti-apoptotic effects to protect kidney function (154). For example, in the mouse model of AKI induced by sepsis, SIRT1 activity is significantly decreased. However, if the SIRT1 activity was increased by resveratrol, the damage of mouse mitochondria will be reduced and the survival time will be significantly prolonged (155). Cisplatin is a commonly used anti-tumor drug, but it is also associated with an increased risk of causing serious side effects, such as
AKI. Its pathogenesis is related to a number of factors, such as mitochondrial damage, oxidative stress and apoptosis (156). Inducing AKI in SIRT3-deficient mice and wild-type mice using cisplatin revealed that the SIRT3-deficient mice suffered more severe kidney damage and even death (157). Further study reported that the expression of SIRT3 was significantly decreased in kidney cells of cisplatin-induced AKI. Due to the loss of SIRT3 regulation, mitochondria are damaged and unable to carry out normal functions (158). If the activity of SIRT3 is restored by treating with the adenosine monophosphate-activated protein kinase activator AICAR or Acetyl-L-Carnitine, the symptoms of AKI are relieved to some extent (157). Ning et al (159) demonstrated that short-term caloric restriction could protect AKI induced by cisplatin in aged rats because it has anti-apoptotic effects and promotes the expression of SIRT1. Although the current treatment of AKI is still limited to intravenous rehydration, diuretic therapy and continuous renal replacement therapy, the study of the relationship between protein acetylation and AKI is useful (160). These results suggest that restoring the activity of SIRT1/3 may be a novel therapeutic target for AKI. Using resveratrol, the activity of SIRT1/3 can be restored efficiently (161). In addition, oxidative stress and mitochondrial function of renal tubular epithelial cells tend to be ameliorated (155). Also, dexmedetomidine plays a role in treating AKI because it induces the upregulation SIRT3 (162).

Heart diseases. Congenital heart disease (CHD) is the most common type of congenital malformation (163). The main cause of CHD is the failure of heart or blood vessel formation and dysplasia during embryonic development (164). Additionally, it is also the result of structural and functional abnormalities caused by the channel failing to close automatically after birth (164). Wu et al (165) induced the abnormal expression of crucial genes in cardiac development by exposing mice to sodium valproate to decrease the activity of KDACs. This experiment led to malformation of the heart, and indicated that acetylation modification may be related to $\mathrm{CHD}$. There have also been experiments that use ethanol and metabolites of ethanol to increase the degree of acetylation of H3K9 (166). It has been found that cardiac precursor cells are abnormally differentiated (165). Study has also reported that valproic acid may cause teratogenic effects by directly inhibiting expression levels and activity of $\mathrm{KDAC}$, thus leading to an imbalance in the ratio of acetylation/deacetylation. As a result of this, the expression levels of VANGL planar cell polarity protein 2, scribble planar cell polarity protein and Rac family small GTPase 1 , the key genes of the H9C2 cardiomyocyte planar cell polarity pathway, are decreased (134), which can lead to CHD. Schlesinger et al (135) screened multiple acetylation sites and found that the acetylation levels of H3K9 and H3K14 had significant effects on the expression of NK2 homeobox 5 , methyltransferase like 2A, GATA binding protein 4 and serum response factor, which are important factors involved in cardiac development. If the expression of KAT2A in H3K9 is downregulated, the development process of mesenchymal stem cells into myocardium will be blocked, resulting in abnormal myocardial development (167). 
In addition to CHD, protein acetylation may also be associated with heart disease caused by oxidative damage (168). During oxidative stress, the content of SIRT3 in mitochondria and nucleus of cardiomyocytes increased significantly (169). It is speculated that SIRT3 is associated with heart disease (168). In a previous study, ku70 was used as a target protein of SIRT3, thereby promoting the interaction between ku70 and the proapoptotic protein Bax. When a stress response is present, SIRT3 protects cardiomyocytes effectively by blocking the translocation of Bax to the mitochondria and preventing cytotoxic stress-mediated cell death (169). Meanwhile, it has been demonstrated that the decrease in cardiac metabolic activity in patients with diabetes may be related to the decreased pyruvate transport activity induced by acetylation of mitochondrial pyruvate carriers 2 (137). As a crucial regulator for myocardial ischemia and reperfusion injury, HDAC4 overexpression increases autophagy microtubule-associated protein light chain 3 and active caspase 3, decreases superoxide dimutase 1 in the myocardium, and ultimately promotes myocardial ischemia/reperfusion injuries (170). Myocardial fibrosis is common in patients with CHD (171); it has reported that HDAC overactivation causes atrial fibrosis and HDAC inhibitors have been demonstrated to be useful in the treatment of heart diseases. Therefore, regulating the activity of HDACs may be a possible therapeutic target of CHD (172). Curcumin, the main ingredient of turmeric, which inhibits p300 activity, prevents the development of cardiomyocyte hypertrophy that leads to heart dysfunction. As a result of this, curcumin could be a positive therapeutic method to aid in the treatment of heart diseases (173).

Cancer. The acetylation of some proteins may have an impact on the occurrence of cancer. Colon cancer-associated transcription factor 1 (CCAT1) is significantly higher in esophageal squamous cell carcinoma (ESCC) cells compared with corresponding non-tumor tissue cells (174). As commonly known, high expression of CCAT1 promotes cell proliferation and invasion, while downregulation of CCAT1 can inhibit cell proliferation and invasion (175). It has been demonstrated that the acetylation of $\mathrm{H} 3 \mathrm{~K} 27$ can partially upregulate the expression of CCAT1, which has the potential to induce cancer (176). Apart from TFs, the proliferation of cancer cells requires glycolysis to provide a large amount of energy. Phosphoglycerate kinase 1 (PGK1) is an important reductase in the glycolysis process, and the functional changes as a result of its acetylation may also be closely related to the changes in cancer cell proliferation. Using liver cancer cells, acetylation of K323 at PGK1 upregulates its activity and enhances its proliferative capacity (138).

The deacetylation of certain proteins is also very important in the occurrence of cancer. Forkhead box protein $\mathrm{O} 1$ (FoxO1) is a tumor suppressor that mediates autophagy, specifically autophagy that is produced by oxidative stress and serum starvation in cancer cells (177). In the cytosol, SIRT2 binds to FoxO1 to deacetylate it and inhibit FoxO1-mediated autophagy. When a stress response occurs, SIRT2 is separated from FoxO1 and results in the acetylation of FoxO1. This process will promote autophagy and finally lead to cell death. This mechanism links the autophagy signal pathway to cancer and is regulated by the acetylation of FoxO1 (178).
SIRT7 was demonstrated to be overexpressed in colorectal cancer cells compared with normal cells. Additionally, SIRT7 is an important facilitator of metastasis in human colorectal cancers, whose overexpression leads to lung and skin metastases (179). Abnormal SIRT7 overexpression accelerates cancer cell growth and enhances invasiveness, and leads to the upregulation of mesenchymal markers vimentin and fibronectin (179). It has reported that SIRT7 can cause carcinogenic transformation of human cancer cells by deacetylating H3K18 (66). In pancreatic cancer, upregulation or downregulation of HDAC6 expression has no significant effect on cancer cell proliferation and cell cycle progression, but overexpression of HDAC6 in combination with cytoplasmic linker protein-170 can enhance cancer cell migration activity significantly (180).

In recent years, KDACIs have been found to be effective in treating diseases such as diabetes, heart disease, chronic fibrosis and cancer (181-184). If the balance of acetylation/deacetylation becomes dysregulated, several physiological and pathological cellular processes will be disrupted and some genes will be abnormally expressed and become carcinogenic factors, eventually leading to diseases $(184,185)$. KDACs can deacetylate histones, which positively charges them again. This will result in tight binding of histones to DNA and make this section of the gene difficult to transcribe. However, KDACIs can selectively inhibit the deacetylation of certain cancer suppressor genes, including p53, TGF $\beta$ type II receptor gene, and restores their transcriptional activity (184). Therefore, indicating that KDACIs may show anticancer effects.

A number of studies have shown that a large proportion of histones have a low degree of acetylation, and this discovery has led to the use of KDACIs in the treatment of cancer (186-189). KDACIs can slow down the proliferation rate of cancer cells, which may inhibit the growth of cancer cells and eventually lead to apoptosis (190). Comparing the targets of two HDAC inhibitors, SAHA and MS-275, KDACIs have a high substrate specificity and provide an important basis for the treatment application of KDACIs (14). In addition, a number of studies have demonstrated that KDACIs can inhibit cancer cells and reduce the resistance of cancer cells to other drugs, which makes it possible to use KDACIs in combination with other drugs to treat cancer (191). There are studies showing that KDACIs can promote the differentiation of CSCs to treat cancer $(192,193)$. It has reported that HDACIs can induce the differentiation of cancer cells to assist cancer therapy by affecting the developmental signaling pathway. These findings could suggest that the underlying mechanisms of KDACIs in cancer therapy may be diverse (193). Resveratrol is a type of natural polyphenolic KDACI that has been studied a large amount. The main target of resveratrol is SIRT1, which has achieved initial success in the treatment of tumor diseases, such as liver cancer and breast cancer (194). Li et al (195) cultured PC-3 and LNCaP prostate cancer cell lines, which were induced by lipopolysaccharides to produce EMT. After being treated with resveratrol, these cells showed significant changes. The results revealed that EMT no longer occurred, and the mesenchymal cells restored the epithelial cell phenotype. This study further promoted the treatment application of resveratrol in cancer (195). However, due to the lack of development of detection techniques, the use of KDACIs to treat cancer has only achieved some initial 


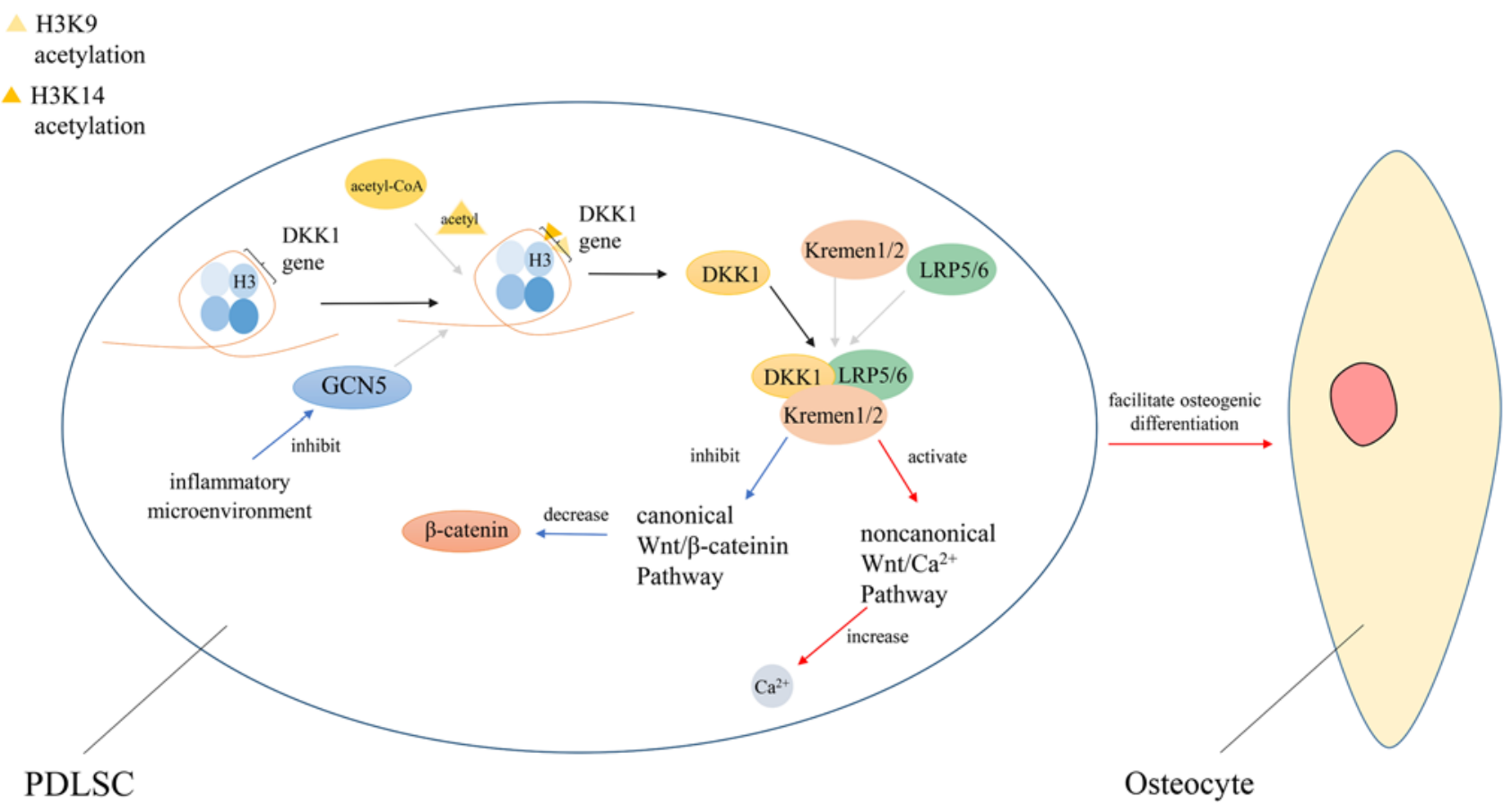

Figure 3. GCN5 enhances the osteogenic differentiation of PDLSCs. GCN5 is a type of KAT that catalyzes the acetylation of H3K9 and H3K14, and promotes the expression of DKK1. As a secreted protein, DKK1 can form trimers with LRP5/6 and Kremen1/2, inhibit the Wnt/ $/$-catenin pathway, and activate the $\mathrm{Wnt} / \mathrm{Ca}^{2+}$ pathway. The decrease of $\beta$-catenin and the increase of $\mathrm{Ca}^{2+}$ ultimately facilitates osteogenic differentiation of PDLSCs. GCN5, general control of amino acid synthesis protein 5; PDLSCs, periodontal ligament stem cells; KATs, lysine acetyltransferases; DKK1, dickkopf-related protein 1; LRP5/6, LDL-receptor-related protein 5/6.

results, and numerous mechanisms have not been studied in detail. Moreover, KDACIs have limitations in the inhibition of cancer. So, most of the drugs based on this have stayed in the clinical trial stage and have not been officially put into use.

\section{Protein acetylation and deacetylation in stem cells}

Stem cells are a type of pluripotent cell that can self-replicate and differentiate to produce other types of cells or divide to produce a large number of cells of the same type. They can be used for tissue and organ regeneration, and they have very broad clinical application prospects. It is currently known that acetylation of histones can regulate physiological activities, such as glycolysis, and thereby regulate the differentiation ability of stem cells (196).

Embryonic stem cells (ESCs) are isolated from early embryos or primitive gonads. Previous study has reported that the level of acetylation of $\mathrm{H} 3 \mathrm{~K} 9$ is related to the reprogramming ability of ESCs by analyzing multiple chromatin markers. The reprogramming ability of ESCs, of which the level of $\mathrm{H} 3 \mathrm{~K} 9$ acetylation is low, is also relatively weak. If $\mathrm{KDACI}$ is added to ESC colonies, its reprogramming ability is significantly improved (197). Actin-like protein $6 a$ is a component of the ATP-dependent histone acetylation complexes. If it is knocked out, the pluripotency of ESCs will decrease (198). In neural stem cells cultured in vitro, the level of acetylation of $\mathrm{H} 3 \mathrm{~K} 9$ decreased first and then increased with the differentiation process. If KDACI is added to increase acetylation levels during the first 4 days of differentiation, cell pluripotency will be promoted and neural differentiation will be inhibited (199). The radiosensitivity of normal stem cells is higher compared with their isogenic differentiated progeny, and the DNA damage response of normal stem cells is stronger compared with their isogenic differentiated progeny. However, if $\mathrm{H} 3 \mathrm{~K} 56$ acetylation in stem cells is downregulated, their radiosensitivity is significantly decreased and survival rate is significantly increased (200).

Here is a particular example of acetylation regulating stem cell differentiation. In patients with periodontitis, periodontal ligament stem cells (PDLSCs), which are a novel population of mesenchymal stem cells, exhibit defects in osteogenic differentiation (201). Also, this may be due to the downregulation of GCN5 expression in a micro-inflammatory environment. GCN5 can induce H3K9 and H3K14 acetylation in the dickkopf-related protein 1 (DKK1) promoter region, thereby regulating the expression level of DKK1. DKK1 can inhibit the Wnt/ $\beta$-catenin signaling pathway by binding to LDL-receptor-related protein 5/6 (LRP5/6) and Kremen1/2, and enhance the osteogenic differentiation of PDLSCs. If GCN5 is knocked out, the expression level of DKK1 decreases, resulting in decreased osteogenic differentiation of PDLSCs (Fig. 3) (202-204). Acetylation can also indirectly regulate the proliferation of stem cells. For example, SIRT6 is involved in maintaining the stability of the Wnt signaling pathway and SIRT6 deletion results in aberrant activation of the Wnt signaling pathway and promote the proliferation of hematopoietic stem cells (205).

Notably, acetylation and cancer stem cells (CSCs) are also closely associated (206). In liver CSCs, there is high expression of HDAC3. If HDAC3 is knocked out by a specific inhibitor, stem cell markers, such as Nanog and Oct4, are expressed at low levels (207). HDAC1 has an inhibitory effect 
on the expression of markers of cervical CSCs (208). HDAC1 can form a complex with lysine demethylase 1A, DNA methyltransferase 1 and lysine-specific demethylase 6A. This complex has the function of reducing the level of acetylation on the EMT-related TFs and inhibiting the proliferation of breast cancer CSCs (209). As a KDACI, abexinostat can induce the differentiation of CSCs from low-dose-sensitive breast cancer cell lines, but has no significant effect on high-dose-sensitive breast cancer cell lines. Therefore, it's necessary to choose an $\mathrm{X}$-inactive specific transcript as a biomarker to select a population suitable for this treatment (210).

At present, methods to affect stem cell activity by acetylation have been applied to clinical treatments. Imatinib is a tyrosine kinase inhibitor for the treatment of chronic myeloid leukemia (CML), but has poor clearance for inactive leukemia stem cells (211). SIRT1 protein was labeled with an anti-SIRT1 antibody and SIRT1 expression was detected by western blotting. It was found that the expression of SIRT1 in CML CD34+ cells in chronic and blast phase was much greater than that of normal cells. It is speculated that SIRT1 inhibitors can be used in combination with imatinib to treat CML to enhance efficacy (212). Different acetylation sites are regulated to varying degrees during differentiation, which plays an important role in regulating the differentiation direction of pluripotent stem cells and monitoring stem cell differentiation (213). In addition to the role mentioned above, acetylation may also play vital role in regulating stem cell self-renewal and cell cycle (214).

\section{Tools to predict acetylation sites}

In the process of studying protein acetylation, it was found that the acetylation site is first step to understand acetylation mechanism (215). Therefore, it is critical to predict acetylation sites with relatively simple methods. Bioinformatics is a new subject derived from the rapid development of biological sciences and computer science. It uses computer programs as a tool to retrieve and analyze biological data. The method obtains relevant information via the databases and processes the data to achieve the goal. As commonly known, bioinformatics methods have played an important role in the field of genomics and proteomics (216). There are some computational models that have been developed to predict acetylation sites.

One of these methods is called LAceP. The first step in this method, researchers need to collect data on protein and acetylation sites in the SysPTM2 and PhosphoSitePlus databases. By this way, researchers can obtain a certain number of acetylation sites in the protein after eliminating redundancy, and use this data as positive data. Then, a peptide containing lysine is selected from the acetylated protein, and negative data is obtained after knocking out the fragment containing the lysine acetylation site. After that, a sliding window strategy is used to determine the optimal length of the acetylated peptide. The homology of the peptides is carried out via the CD-hit software to avoid model over fitting. If the similarity of the two peptides exceeds $70 \%$, they will be classified as one class. Only one of them will be retained while the other peptides will be discarded. The model uses three types of features, which are amino acid physicochemical property, transition probability matrix and position-specific symbol composition, to predict lysine acetylation sites. Because the calculations are performed by different algorithms, the probability of acetylation may be analyzed from three aspects. Then, the classification of the peptides in the training datasets, their class tags and features were used as input of the logistic regression model. After model training, the optimized parameters are generated as outputs. Researchers can analyze the probability of amino acid acetylation base on these data (215).

Another method is called ASEB. Firstly, it is necessary to collect acetylated human proteins from different families using PubMed. In this step, researchers need to query the detailed acetylation sites and KATs, and go to the UniProt database to obtain the UniProt IDs corresponding to the acetylated proteins. Then, using the idea of Gene Set Enrichment Analysis, the ASEB method was developed to form an acetylated polypeptide, which consists of the acetylation site, its first eight amino acids and its last eight amino acids. Different KAT families form different acetylated peptide groups. In order to determine whether a given peptide can be acetylated by a certain KAT family, it is only necessary to analyze how similar the given peptide is to the acetylated peptide in that family. For analysis, a set of predefined KAT specific polypeptides, including $\mathrm{N}$-polypeptides, is inputted. Then, the similarity between the given polypeptide fragment and the peptide contained therein is searched in the set. The background peptide set can be calculated by BLOSUM 62 matrix. If the similarity with the polypeptide in a certain KAT family is extremely high, it will be possible that the polypeptide is a new substrate of the KAT family. Then, the enrichment score is calculated and estimated to obtain the relatively significant chance that the given peptides were acetylated by the KAT family (217).

GPS-PAIL, one of these methods, contains 702 known HAT-specific acetylation sites in 205 proteins for seven HATs, including CREBBP, p300, HAT1, KAT2A, KAT2B, KAT5 and KAT8, developed from the scientific literature and public data resources. The method predicts acetylation sites based on the principle that different HATs have distinct sequence specificities for the substrate modifications. GPS-PAIL develop a computational model for each HAT by training a previously established algorithm of Group-Based Prediction System. Online service and stand-alone packages of GPS-PAIL are also provided. The two tools mentioned above have their own distinct advantages on the inputting of the online service, which contained three parts: i) HAT types; ii) the protein sequences; and iii) four thresholds, including 'High', 'Medium', 'Low' and 'All' (218).

Moreover, other methods, such as N-Ace and PLMLA, are applied to predict acetylation sites. N-Ace predicts the protein acetylation sites based on the support of vector machine. The training of $\mathrm{N}$-Ace depends on the amino acid sequence and other structural characteristics; it has higher predictive accuracy compared with models trained using only amino acid sequences (8). PLMLA combines protein sequences, secondary structures and amino acid properties to predict the methylation and acetylation of lysine residues in protein sequences (219).

In conclusion, LAceP, N-Ace and PLMLA are unable to predict HAT-specific acetylation sites. Compared with ASEB, LAceP can carry out acetylation peptide length assays and takes 
more consideration to peptide redundancy and residue property, which may have an important impact on acetylation. In addition, LAceP has the potential for improved performance in the future when considering the Matthews correlation coefficient measurement. Conversely, ASEB have the ability to determine KATs are responsible for the acetylation of given proteins. The present version only predicts acetylation catalyzed by two KAT families, including CBP/p300 and GCN5/PCAF. Both GPS-PAIL and ASEB can predict HAT-specific acetylation sites. However, in general, GPS-PAIL generated an improved performance compared with ASEB. All of them have a high level of accuracy $(8,215,217-219)$.

The use of bioinformatics to predict acetylation sites greatly facilitates the study of acetylation, and saves a lot of invaluable research time. The integration of the properties of different acetylated peptides is also conducive to the study of the functions and characteristics of protein acetylation.

\section{Conclusions and prospects}

Histone acetylation and non-histone protein acetylation are important for human biological functions, and are closely related to the mechanisms of various diseases. At present, the study process of PTM is still steadily advancing. The process of acetylation together with other modifications, such as methylation and glycosylation, regulates biological activities and its role in the whole metabolic network still needs further research. Moreover, the constant innovation of theory is destined to provide more space and possibility for clinical application. In-depth study of protein acetylation could lead to novel prospects in the clinical treatment of a number of diseases. The regulation of TFEB acetylation and deacetylation may be a useful biological process in the development of Alzheimer's disease and renal injury. The acetylation of E2F1 is associated with the treatment of lung cancer. Additionally, Snail has also been demonstrated as an effective target for cancer therapy. The effect of HDAC6 on Hsp90 is expected to promote the development strategies of breast cancer treatment. Activation of KDACs participates in the process of renal regeneration and repair, and plays different roles in AKI. By mediating the expression of KAT2A, HDAC and p300, the development process of CHD can be inhibited. Moreover, CCAT1 acetylation is associated with ESCC, and the PGK1 acetylation and deacetylation may be a promising target for cancer treatment. Also, FoxO1 acetylation and the expression of SIRT7 are associated with cancer. At present, KDACIs have been used in the treatment of diseases, such as diabetes, heart disease, chronic fibrosis and cancer. Protein acetylation is increasingly related to clinical treatment, which provides novel ideas and methods for the treatment of numerous intractable diseases.

\section{Acknowledgements}

Not applicable.

\section{Funding}

This work was supported by the Distinguished Professorship Program of National Research Program on prevention and control of major birth defects in reproductive health (grant no. 2017YFC1000900) and Special-funded Programme on National Key Scientific Instruments and Equipment Development (grant no. 2016YFF0103800).

\section{Availability of data and materials}

Not applicable.

\section{Authors' contributions}

CX and YT conceived and drafted the manuscript. ML and TC contributed to the literature retrieval and manuscript modification. JQ supervised and designed the present study and contributed to the approval of the final version of the manuscript. All authors read and approved the final manuscript.

\section{Ethics approval and consent to participate}

Not applicable.

\section{Patient consent for publication}

Not applicable.

\section{Competing interests}

The authors declare that they have no competing interests.

\section{References}

1. Marsh JA and Forman-Kay JD: Sequence determinants of compaction in intrinsically disordered proteins. Biophysical J 98: 2383-2390, 2010.

2. Bah A and Forman-Kay JD: Modulation of intrinsically disordered protein function by post-translational modifications. J Biol Chem 291: 6696-6705, 2016.

3. Adaniya SM, O-Uchi J, Cypress MW, Kusakari Y and Jhun BS: Posttranslational modifications of mitochondrial fission and fusion proteins in cardiac physiology and pathophysiology. Am J Physiol Cell Physiol 316: C583-C604, 2019.

4. Ametzazurra A, Larrea E, Civeira MP, Prieto J and Aldabe R Implication of human $\mathrm{N}$-alpha-acetyltransferase 5 in cellular proliferation and carcinogenesis. Oncogene 27: 7296-7306, 2008.

5. Christensen DG, Baumgartner JT, Xie X, Jew KM, Basisty N, Schilling B, Kuhn ML and Wolfe AJ: Mechanisms, detection, and relevance of protein acetylation in prokaryotes. mBio 10: e02708-18, 2019.

6. Drazic A, Myklebust LM, Ree R and Arnesen T: The world of protein acetylation. Biochim Biophys Acta 1864: 1372-1401, 2016.

7. Verdin E and Ott M: 50 years of protein acetylation: From gene regulation to epigenetics, metabolism and beyond. Nat Rev Mol Cell Biol 16: 258-264, 2015

8. Lee TY, Hsu JB, Lin FM, Chang WC, Hsu PC and Huang HD N-Ace: Using solvent accessibility and physicochemical properties to identify protein N-acetylation sites. J Comput Chem 31: 2759-2771, 2010 .

9. Hollebeke J, Van Damme P and Gevaert K: N-terminal acetylation and other functions of Nalpha-acetyltransferases. Biol Chem 393: 291-298, 2012

10. Thao S, Chen CS, Zhu $\mathrm{H}$ and Escalante-Semerena JC: Nepsilon-lysine acetylation of a bacterial transcription factor inhibits Its DNA-binding activity. PLoS One 5: e15123, 2010.

11. Yang XJ and Gregoire S: Metabolism, cytoskeleton and cellular signalling in the grip of protein Nepsilon- and O-acetylation. EMBO Rep 8: 556-562, 2007.

12. Allfrey VG, Faulkner R and Mirsky AE: Acetylation and methylation of histones and their possible role in the regulation of RNA synthesis. Proc Natl Acad Sci USA 51: 786-794, 1964. 
13. Verdone L, Caserta M and Di Mauro E: Role of histone acetylation in the control of gene expression. Biochem Cell Biol 83: 344-353, 2005

14. Choudhary C, Kumar C, Gnad F, Nielsen ML, Rehman M, Walther TC, Olsen JV and Mann M: Lysine acetylation targets protein complexes and co-regulates major cellular functions. Science 325: 834-840, 2009.

15. Allis CD, Berger SL, Cote J, Dent S, Jenuwien T, Kouzarides T, Pillus L, Reinberg D, Shi Y, Shiekhattar R, et al: New nomenclature for chromatin-modifying enzymes. Cell 131: 633-636, 2007.

16. Li P, Ge J and Li H: Lysine acetyltransferases and lysine deacetylases as targets for cardiovascular disease. Nat Rev Cardiol 17 96-115, 2020

17. Song L, Wang G, Malhotra A, Deutscher MP and Liang W: Reversible acetylation on Lys501 regulates the activity of RNase II. Nucleic Acids Res 44: 1979-1988, 2016.

18. Sterner DE and Berger SL: Acetylation of histones and transcription-related factors. Microbiol Mol Biol Rev 64: 435-459, 2000.

19. Ruhlmann F, Windhof-Jaidhauser IM, Menze C, Beißbarth T, Bohnenberger $\mathrm{H}$, Ghadimi $\mathrm{M}$ and Dango S: The prognostic capacities of CBP and p300 in locally advanced rectal cancer. World J Surg Oncol 17: 224, 2019.

20. Narita T, Weinert BT and Choudhary C: Functions and mechanisms of non-histone protein acetylation. Nat Rev Mol Cell Biol 20: 156-174, 2019.

21. Hwang CS, Shemorry A and Varshavsky A: N-terminal acetylation of cellular proteins creates specific degradation signals. Science 327: 973-977, 2010.

22. Vetting MW, S de Carvalho LP, Yu M, Hegde SS, Magnet S, Roderick SL and Blanchard JS: Structure and functions of the GNAT superfamily of acetyltransferases. Arch Biochem Biophys 433: 212-226, 2005.

23. Ruiz-Garcia AB, Sendra R, Galiana M, Pamblanco $M$, Perez-Ortin JE and Tordera V: HAT1 and HAT2 proteins are components of a yeast nuclear histone acetyltransferase enzyme specific for free histone H4. J Biol Chem 273: 12599-12605, 1998.

24. Miskiewicz K, Jose LE, Bento-Abreu A, Fislage M, Taes I Kasprowicz J, Swerts J, Sigrist S, Versées W, Robberecht W and Verstreken P: ELP3 controls active zone morphology by acetylating the ELKS family member Bruchpilot. Neuron 72: 776-788, 2011.

25. Sampath V, Liu B, Tafrov S, Srinivasan M, Rieger R, Chen EI and Sternglanz R: Biochemical characterization of $\mathrm{Hpa} 2$ and $\mathrm{Hpa} 3$, two small closely related acetyltransferases from Saccharomyces cerevisiae. J Biol Chem 288: 21506-21513, 2013

26. Sapountzi V and Cote J: MYST-family histone acetyltransferases: Beyond chromatin. Cell Mol Life Sci 68: 1147-1156, 2011.

27. Reiter C, Heise F, Chung HR and Ehrenhofer-Murray AE: A link between Sas2-mediated H4 K16 acetylation, chromatin assembly in S-phase by CAF-I and Asf 1, and nucleosome assembly by Spt6 during transcription. FEMS Yeast Res 15: fov073, 2015.

28. Church M, Smith KC, Alhussain MM, Pennings S and Fleming AB: Sas3 and Ada2(Gcn5)-dependent histone H3 acetylation is required for transcription elongation at the de-repressed FLO1 gene. Nucleic Acids Res 45: 4413-4430, 2017.

29. Yan Y, Barlev NA, Haley RH, Berger SL and Marmorstein R: Crystal structure of yeast Esal suggests a unified mechanism for catalysis and substrate binding by histone acetyltransferases. Mol Cell 6: 1195-1205, 2000.

30. Wang F, Marshall CB and Ikura M: Transcriptional/epigenetic regulator $\mathrm{CBP} / \mathrm{p} 300$ in tumorigenesis: Structural and functional versatility in target recognition. Cell Mol Life Sci 70: 3989-4008, 2013.

31. Hu LI, Lima BP and Wolfe AJ: Bacterial protein acetylation: The dawning of a new age. Mol Microbiol 77: 15-21, 2010

32. Pelletier N, Champagne N, Stifani S and Yang XJ: MOZ and MORF histone acetyltransferases interact with the Runt-domain transcription factor Runx2. Oncogene 21: 2729-2740, 2002

33. Rokudai S, Laptenko O, Arnal SM, Taya Y, Kitabayashi I and Prives C: MOZ increases p53 acetylation and premature senescence through its complex formation with PML. Proc Natl Acad Sci USA 110: 3895-3900, 2013

34. Fournier M, Orpinell M, Grauffel C, Scheer E, Garnier JM, Ye T, Chavant V, Joint M, Esashi F, Dejaegere A, et al: KAT2A/KAT2B-targeted acetylome reveals a role for PLK4 acetylation in preventing centrosome amplification. Nat Commun 7: 13227, 2016.

35. Bao X, Liu H, Liu X, Ruan K, Zhang Y, Zhang Z, Hu Q, Liu Y, Akram S, Zhang J, et al: Mitosis-specific acetylation tunes Ran effector binding for chromosome segregation. J Mol Cell Biol 10: $18-32,2018$.
36. Ghosh TK, Aparicio-Sanchez JJ, Buxton S, Ketley A, Mohamed T, Rutland CS, Loughna S and Brook JD: Acetylation of TBX5 by KAT2B and KAT2A regulates heart and limb development. J Mol Cell Cardiol 114: 185-198, 2018.

37. Cheng X, Ma X, Zhu Q, Song D, Ding X, Li L, Jiang X, Wang X, Tian R, Su H, et al: Pacer is a mediator of mTORC1 and GSK3-TIP60 signaling in regulation of autophagosome maturation and lipid metabolism. Mol Cell 73: 788-802.e7, 2019.

38. Miotto B and Struhl K: HBO1 histone acetylase is a coactivator of the replication licensing factor Cdt1. Genes Dev 22: 2633-2638, 2008.

39. Yuan H, Rossetto D, Mellert H, Dang W, Srinivasan M, Johnson J, Hodawadekar S, Ding EC, Speicher K, Abshiru N, et al: MYST protein acetyltransferase activity requires active site lysine autoacetylation. EMBO J 31: 58-70, 2012.

40. Chang R, Zhang Y, Zhang P and Zhou Q: Snail acetylation by histone acetyltransferase p300 in lung cancer. Thoracic Cancer 8: 131-137, 2017

41. Yang Y, Cui J, Xue F, Zhang C, Mei Z, Wang Y, Bi M, Shan D, Meredith A, Li H and Xu ZQ: Pokemon (FBI-1) interacts with Smad4 to repress TGF- $\beta$-induced transcriptional responses. Biochim Biophys Acta 1849: 270-281, 2015.

42. Cazzalini O, Sommatis S, Tillhon M, Dutto I, Bachi A, Rapp A Nardo T, Scovassi AI, Necchi D, Cardoso MC, et al: CBP and p300 acetylate PCNA to link its degradation with nucleotide excision repair synthesis. Nucleic Acids Res 42: 8433-8448, 2014.

43. Senf SM, Sandesara PB, Reed SA and Judge AR: p300 Acetyltransferase activity differentially regulates the localization and activity of the FOXO homologues in skeletal muscle. Am J Physiol Cell Physiol 300: C1490-C1501, 2011.

44. Lee K and Seo PJ: The HAF2 protein shapes histone acetylation levels of PRR5 and LUX loci in Arabidopsis. Planta 248 513-518, 2018.

45. Nakakura T, Nemoto T, Suzuki T, Asano-Hoshino A, Tanaka H, Arisawa K, Nishijima Y, Kiuchi Y and Hagiwara H: Adrenalectomy facilitates ATAT1 expression and alpha-tubulin acetylation in ACTH-producing corticotrophs. Cell Tissue Res 366: 363-370, 2016.

46. Zhang J, Shi X, Li Y, Kim BJ, Jia J, Huang Z, Yang T, Fu X, Jung SY, Wang Y, et al: Acetylation of Smc3 by Ecol is required for $\mathrm{S}$ phase sister chromatid cohesion in both human and yeast. Mol Cell 31: 143-151, 2008.

47. Wu H, Moshkina N, Min J, Zeng H, Joshua J, Zhou MM and Plotnikov AN: Structural basis for substrate specificity and catalysis of human histone acetyltransferase 1. Proc Natl Acad Sci USA 109: 8925-8930, 2012

48. de Ruijter AJ, van Gennip AH, Caron HN, Kemp S and van Kuilenburg AB: Histone deacetylases (HDACs): Characterization of the classical HDAC family. Biochem J 370: 737-749, 2003.

49. Banik D, Moufarrij S and Villagra A: Immunoepigenetics combination therapies: An overview of the role of HDACs in cancer immunotherapy. Int J Mol Sci 20: 2241, 2019.

50. Parra M: Class IIa HDACs-new insights into their functions in physiology and pathology. FEBS J 282: 1736-1744, 2015.

51. Muller BM, Jana L, Kasajima A, Lehmann A, Prinzler J, Budczies J, Winzer KJ, Dietel M, Weichert W and Denkert C: Differential expression of histone deacetylases HDAC1, 2 and 3 in human breast cancer-overexpression of HDAC2 and HDAC3 is associated with clinicopathological indicators of disease progression. BMC Cancer 13: 215, 2013.

52. Miller KM, Tjeertes JV, Coates J, Legube G, Polo SE, Britton S and Jackson SP: Human HDAC1 and HDAC2 function in the DNA-damage response to promote DNA nonhomologous end-joining. Nat Struct Mol Biol 17: 1144-1151, 2010.

53. Saito S, Zhuang Y, Suzuki T, Ota Y, Bateman ME, Alkhatib AL, Morris GF and Lasky JA: HDAC8 inhibition ameliorates pulmonary fibrosis. Am J Physiol Lung Cell Mol Physiol 316: L175-L186, 2019.

54. Winbanks CE, Wang B, Beyer C, Koh P, White L, Kantharidis P and Gregorevic P: TGF-beta regulates miR-206 and miR-29 to control myogenic differentiation through regulation of HDAC4. J Biol Chem 286: 13805-13814, 2011.

55. Cho Y, Sloutsky R, Naegle KM and Cavalli V: Injury-induced HDAC5 nuclear export is essential for axon regeneration. Cell 155: 894-908, 2013.

56. Bradley EW, Carpio LR, Olson EN and Westendorf JJ: Histone deacetylase 7 (Hdac7) suppresses chondrocyte proliferation and $\beta$-catenin activity during endochondral ossification. J Biol Chem 290: 118-126, 2015. 
57. Hu Y, Sun L, Tao S, Dai M, Wang Y, Li Y and Wu J: Clinical significance of HDAC9 in hepatocellular carcinoma. Cell Mol Biol (Noisy-le-Grand) 65: 23-28, 2019.

58. Bitler BG, Wu S, Park PH, Hai Y, Aird KM, Wang Y, Zhai Y, Kossenkov AV, Vara-Ailor A, Rauscher FJ III, et al: ARID1A-mutated ovarian cancers depend on HDAC6 activity. Nat Cell Biol 19: 962-973, 2017.

59. Radhakrishnan R, Li Y, Xiang S, Yuan F, Yuan Z, Telles E, Fang J, Coppola D, Shibata D, Lane WS, et al: Histone deacetylase 10 regulates DNA mismatch repair and may involve the deacetylation of MutS homolog 2. J Biol Chem 290: 22795-22804, 2015.

60. Zerr P, Palumbo-Zerr K, Huang J, Tomcik M, Sumova B Distler O, Schett G and Distler JH: Sirt1 regulates canonical TGF- $\beta$ signalling to control fibroblast activation and tissue fibrosis. Ann Rheum Dis 75: 226-233, 2016.

61. Yuan Q, Zhan L, Zhou QY, Zhang LL, Chen XM, Hu XM and Yuan XC: SIRT2 regulates microtubule stabilization in diabetic cardiomyopathy. Eur J Pharmacol 764: 554-561, 2015.

62. Ahn BH, Kim HS, Song S, Lee IH, Liu J, Vassilopoulos A Deng CX and Finkel T: A role for the mitochondrial deacetylase Sirt3 in regulating energy homeostasis. Proc Natl Acad Sci USA 105: 14447-14452, 2008.

63. Jeong SM, Xiao C, Finley LW, Lahusen T, Souza AL, Pierce K, Li YH, Wang X, Laurent G, German NJ, et al: SIRT4 has tumor-suppressive activity and regulates the cellular metabolic response to DNA damage by inhibiting mitochondrial glutamine metabolism. Cancer Cell 23: 450-463, 2013.

64. Rardin MJ, He W, Nishida Y, Newman JC, Carrico C, Danielson SR, Guo A, Gut P, Sahu AK, Li B, et al: SIRT5 regulates the mitochondrial lysine succinylome and metabolic networks. Cell Metab 18: 920-933, 2013.

65. Kaluski S, Portillo M, Besnard A, Stein D, Einav M, Zhong L, Ueberham U, Arendt T, Mostoslavsky R, Sahay A and Toiber D: Neuroprotective functions for the histone Deacetylase SIRT6. Cell Rep 18: 3052-3062, 2017.

66. Barber MF, Michishita-Kioi E, Xi Y, Tasselli L, Kioi M, Moqtaderi Z, Tennen RI, Paredes S, Young NL, Chen K, et al: SIRT7 links H3K18 deacetylation to maintenance of oncogenic transformation. Nature 487: 114-118, 2012.

67. Yuan L, Chen X, Cheng L, Rao M, Chen K, Zhang N, Meng J, Li M, Yang LT, Yang PC, et al: HDAC11 regulates interleukin-13 expression in CD4+T cells in the heart. J Mol Cell Cardiol 122: $1-10,2018$

68. Sahakian E, Chen J, Powers JJ, Chen X, Maharaj K, Deng SL, Achille AN, Lienlaf M, Wang HW, Cheng F, et al: Essential role for histone deacetylase 11 (HDAC11) in neutrophil biology. J Leukoc Biol 102: 475-486, 2017.

69. Chatterjee SS, Saj A, Gocha T, Murphy M, Gonsalves FC Zhang X, Hayward P, Akgöl Oksuz B, Shen SS, Madar A, et al: Inhibition of $\beta$-catenin-TCF1 interaction delays differentiation of mouse embryonic stem cells. J Cell Biol 211: 39-51, 2015

70. Abu-Elmagd M, Robson L, Sweetman D, Hadley J,Francis-West $P$ and Munsterberg A: Wnt/Lef1 signaling acts via Pitx2 to regulate somite myogenesis. Dev Biol 337: 211-219, 2010.

71. Wapenaar $\mathrm{H}$ and Dekker FJ: Histone acetyltransferases: Challenges in targeting bi-substrate enzymes. Clin Epigenetics 8 : 59, 2016.

72. Chen GD, Yu WD and Chen XP: SirT1 activator represses the transcription of TNF $\alpha$ in THP1 cells of a sepsis model via deacetylation of H4K16. Mol Med Rep 14: 5544-5550, 2016.

73. Michishita E, McCord RA, Berber E, Kioi M, Padilla-Nash H, Damian M, Cheung P, Kusumoto R, Kawahara TL, Barrett JC, et al: SIRT6 is a histone H3 lysine 9 deacetylase that modulates telomeric chromatin. Nature 452: 492-496, 2008.

74. Kim TK and Shiekhattar R: Architectural and functional commonalities between enhancers and promoters. Cell 162 948-959, 2015.

75. Rada-Iglesias A, Bajpai R, Swigut T, Brugmann SA, Flynn RA and Wysocka $\mathrm{J}$ : A unique chromatin signature uncovers early developmental enhancers in humans. Nature 470: 279-283, 2011.

76. Pradeepa MM, Grimes GR, Kumar Y, Olley G, Taylor GC, Schneider R and Bickmore WA: Histone H3 globular domain acetylation identifies a new class of enhancers. Nat Genet 48 : 681-686, 2016

77. Pradeepa MM: Causal role of histone acetylations in enhancer function. Transcription 8: 40-47, 2017.

78. Dhar S, Gursoy-Yuzugullu O, Parasuram R and Price BD: The tale of a tail: Histone $\mathrm{H} 4$ acetylation and the repair of DNA breaks. Philos Trans R Soc Lond B Biol Sci 372: 20160284, 2017.
79. Noguchi C, Singh T, Ziegler MA, Peake JD, Khair L, Aza A, Nakamura TM and Noguchi E: The NuA4 acetyltransferase and histone $\mathrm{H} 4$ acetylation promote replication recovery after topoisomerase I-poisoning. Epigenetics Chromatin 12: 24 , 2019.

80. Vadla R, Chatterjee N and Haldar D: Cellular environment controls the dynamics of histone $\mathrm{H} 3$ lysine 56 acetylation in response to DNA damage in mammalian cells. J Biosci 45: 19, 2020.

81. Koprinarova M, Schnekenburger M and Diederich M: Role of histone acetylation in cell cycle regulation. Curr Top Med Chem 16: 732-744, 2016.

82. Gao FH, Hu XH, Li W, Liu H, Zhang YJ, Guo ZY, Xu MH, Wang ST, Jiang B, Liu F, et al: Oridonin induces apoptosis and senescence in colorectal cancer cells by increasing histone hyperacetylation and regulation of p16, p21, p27 and c-myc. BMC Cancer 10: 610, 2010.

83. Kim E, Bisson WH, Löhr CV, Williams DE, Ho E, Dashwood RH and Rajendran P: Histone and non-histone targets of dietary Deacetylase inhibitors. Curr Top Med Chem 16: 714-731, 2016.

84. Glozak MA, Sengupta N, Zhang X and Seto E: Acetylation and deacetylation of non-histone proteins. Gene 363: 15-23, 2005

85. Suzuki M, Ikeda A and Bartlett JD: Sirt1 overexpression suppresses fluoride-induced p53 acetylation to alleviate fluoride toxicity in ameloblasts responsible for enamel formation. Arch Toxicol 92: 1283-1293, 2018.

86. Ito A, Lai CH, Zhao X, Saito S, Hamilton MH, Appella E and Yao TP: p300/CBP-mediated p53 acetylation is commonly induced by p53-activating agents and inhibited by MDM2. EMBO J 20: 1331-1340, 2001.

87. Iyer NG, Xian J, Chin SF, Bannister AJ, Daigo Y, Aparicio S, Kouzarides T and Caldas C: p300 is required for orderly G1/S transition in human cancer cells. Oncogene 26: 21-29, 2007.

88. Shi D, Dai C, Qin J and Gu W: Negative regulation of the p300-p53 interplay by DDX24. Oncogene 35: 528-536, 2016.

89. Morton DJ, Patel D, Joshi J, Hunt A, Knowell AE and Chaudhary J: ID4 regulates transcriptional activity of wild type and mutant p53 via K373 acetylation. Oncotarget 8: 2536-2549, 2017.

90. Ou HL and Schumacher B: DNA damage responses and p53 in the aging process. Blood 131: 488-495, 2018.

91. Miyajima C, Kawarada Y, Inoue Y, Suzuki C, Mitamura K, Morishita D, Ohoka N, Imamura T and Hayashi H: Transcriptional Coactivator TAZ negatively regulates tumor suppressor p53 activity and cellular senescence. Cells 9: 171,2020.

92. Reed SM and Quelle DE: p53 Acetylation: Regulation and consequences. Cancers 7: 30-69, 2014.

93. Shan W, Jiang Y, Yu H, Huang Q, Liu L, Guo X, Li L, Mi Q, Zhang K and Yang Z: HDAC2 overexpression correlates with aggressive clinicopathological features and DNA-damage response pathway of breast cancer. Am J Cancer Res 7: 1213-1226, 2017.

94. Zhang L, Kang W, Lu X, Ma S, Dong L and Zou B: Weighted gene co-expression network analysis and connectivity map identifies lovastatin as a treatment option of gastric cancer by inhibiting HDAC2. Gene 681: 15-25, 2019.

95. Brandl A, Wagner T, Uhlig KM, Knauer SK, Stauber RH, Melchior F, Schneider G, Heinzel T and Krämer OH: Dynamically regulated sumoylation of HDAC2 controls p53 deacetylation and restricts apoptosis following genotoxic stress. J Mol Cell Biol 4: 284-293, 2012.

96. Li D, Marchenko ND and Moll UM: SAHA shows preferential cytotoxicity in mutant $\mathrm{p} 53$ cancer cells by destabilizing mutant p53 through inhibition of the HDAC6-Hsp90 chaperone axis. Cell Death Differ 18: 1904-1913, 2011.

97. Marrogi AJ, Khan MA, van Gijssel HE, Welsh JA, Rahim H, Demetris AJ, Kowdley KV, Hussain SP, Nair J, Bartsch H, et al: Oxidative stress and p53 mutations in the carcinogenesis of iron overload-associated hepatocellular carcinoma. J Natl Cancer Inst 93: 1652-1655, 2001.

98. Zhou Y, Que KT, Zhang Z, Yi ZJ, Zhao PX, You Y, Gong JP and Liu ZJ: Iron overloaded polarizes macrophage to proinflammation phenotype through ROS/acetyl-p53 pathway. Cancer Med 7: 4012-4022, 2018

99. Tu W, Zhang Q, Liu Y, Han L, Wang Q, Chen P, Zhang S, Wang $A$ and Zhou X: Fluoride induces apoptosis via inhibiting SIRT1 activity to activate mitochondrial p53 pathway in human neuroblastoma SH-SY5Y cells. Toxicol Appl Pharmacol 347: 60-69, 2018. 
100. Wingelhofer B, Neubauer HA, Valent P, Han X, Constantinescu SN, Gunning PT, Müller M and Moriggl R: Implications of STAT3 and STAT5 signaling on gene regulation and chromatin remodeling in hematopoietic cancer. Leukemia 32: 1713-1726, 2018.

101. Chen Y, Wu R, Chen HZ, Xiao Q, Wang WJ, He JP, Li XX, $\mathrm{Yu} \mathrm{XW}, \mathrm{Li} \mathrm{L}$, Wang P, et al: Enhancement of hypothalamic STAT3 acetylation by nuclear receptor Nur77 dictates leptin sensitivity. Diabetes 64: 2069-2081, 2015.

102.Zheng J, van de Veerdonk FL, Crossland KL, Smeekens SP, Chan CM, Al Shehri T, Abinun M, Gennery AR, Mann J, Lendrem DW, et al: Gain-of-function STAT1 mutations impair STAT3 activity in patients with chronic mucocutaneous candidiasis (CMC). Eur J Immunol 45: 2834-2846, 2015.

103. Ma L, Huang C, Wang XJ, Xin DE, Wang LS, Zou QC, Zhang YS, Tan MD, Wang YM, Zhao TC, et al: Lysyl oxidase 3 is a dual-specificity enzyme involved in STAT3 Deacetylation and Deacetylimination modulation. Mol Cell 65: 296-309, 2017.

104. Hansen DV, Hanson JE and Sheng M: Microglia in Alzheimer's disease. J Cell Biol 217: 459-472, 2018.

105. Dani M, Wood M, Mizoguchi R, Fan Z, Walker Z, Morgan R, Hinz R, Biju M, Kuruvilla T, Brooks DJ and Edison P: Microglial activation correlates in vivo with both tau and amyloid in Alzheimer's disease. Brain 141: 2740-2754, 2018.

106. Eufemi M, Cocchiola R, Romaniello D, Correani V, Di Francesco L, Fabrizi C, Maras B and Schininà ME: Acetylation and phosphorylation of STAT3 are involved in the responsiveness of microglia to beta amyloid. Neurochem Int 81: 48-56, 2015.

107. Xu YS, Liang JJ, Wang Y, Zhao XJ, Xu L, Xu YY, Zou QC, Zhang JM, Tu CE, Cui YG, et al: STAT3 undergoes acetylation-dependent mitochondrial translocation to regulate pyruvate metabolism. Sci Rep 6: 39517, 2016.

108. Gough DJ, Corlett A, Schlessinger K, Wegrzyn J, Larner AC and Levy DE: Mitochondrial STAT3 supports Ras-dependent oncogenic transformation. Science 324: 1713-1716, 2009.

109. Wang Y, Huang Y, Liu J, Zhang J, Xu M, You Z, Peng C, Gong Z and Liu W: Acetyltransferase GCN5 regulates autophagy and lysosome biogenesis by targeting TFEB. EMBO Rep 21: e48335, 2020

110. Bao J, Zheng L, Zhang Q, Li X, Zhang X, Li Z, Bai X, Zhang Z, Huo W, Zhao X, et al: Deacetylation of TFEB promotes fibrillar $\mathrm{A} \beta$ degradation by upregulating lysosomal biogenesis in microglia. Protein Cell 7: 417-433, 2016.

111. Zhang J, Wang J, Zhou Z, Park JE, Wang L, Wu S, Sun X, Lu L, Wang T, Lin Q, et al: Importance of TFEB acetylation in control of its transcriptional activity and lysosomal function in response to histone deacetylase inhibitors. Autophagy 14: 1043-1059, 2018.

112. Brijmohan AS, Batchu SN, Majumder S, Alghamdi TA, Thieme K, McGaugh S, Liu Y, Advani SL, Bowskill BB, Kabir MG, et al: HDAC6 inhibition promotes transcription factor EB activation and is protective in experimental kidney disease. Front Pharmacol 9: 34, 2018.

113. She A, Kurtser I, Reis SA, Hennig K, Lai J, Lang A, Zhao WN, Mazitschek R, Dickerson BC, Herz J and Haggarty SJ Selectivity and kinetic requirements of HDAC inhibitors as progranulin enhancers for treating frontotemporal dementia. Cell Chem Biol 24: 892-906.e5, 2017.

114. Manickavinayaham S, Velez-Cruz R, Biswas AK, Bedford E, Klein BJ, Kutateladze TG, Liu B, Bedford MT and Johnson DG: E2F1 acetylation directs p300/CBP-mediated histone acetylation at DNA double-strand breaks to facilitate repair. Nat Commun 10: 4951, 2019.

115. Chen L, Wei T, Si X, Wang Q, Li Y, Leng Y, Deng A, Chen J, Wang G, Zhu S and Kang J: Lysine acetyltransferase GCN5 potentiates the growth of non-small cell lung cancer via promotion of E2F1, cyclin D1, and cyclin E1 expression. J Biol Chem 288: 14510-14521, 2013.

116. Thiery JP, Acloque H, Huang RY and Nieto MA: Epithelial-mesenchymal transitions in development and disease. Cell 139: 871-890, 2009.

117. Lin Y, Dong C and Zhou BP: Epigenetic regulation of EMT: The snail story. Curr Pharm Des 20: 1698-1705, 2014

118. Hsu DS, Wang HJ, Tai SK, Chou CH, Hsieh CH, Chiu PH, Chen NJ and Yang MH: Acetylation of snail modulates the cytokinome of cancer cells to enhance the recruitment of macrophages. Cancer Cell 26: 534-548, 2014

119. Xu W, Liu H,Liu ZG, Wang HS, Zhang F, Wang H, Zhang J, Chen JJ, Huang HJ, Tan Y, et al: Histone deacetylase inhibitors upregulate Snail via Smad2/3 phosphorylation and stabilization of Snail to promote metastasis of hepatoma cells. Cancer Lett 420: 1-13, 2018.
120. Zhang L, Shan X, Chen Q, Xu D, Fan X, Yu M, Yan Q and Liu J: Downregulation of HDAC3 by ginsenoside Rg3 inhibits epithelial-mesenchymal transition of cutaneous squamous cell carcinoma through c-Jun acetylation. J Cell Physiol 234: 22207-22219, 2019

121. McMahon SB: MYC and the control of apoptosis. Cold Spring Harb Perspect Med 4: a014407, 2014

122. Kenneth NS, Ramsbottom BA, Gomez-Roman N, Marshall L, Cole PA and White RJ: TRRAP and GCN5 are used by c-Myc to activate RNA polymerase III transcription. Proc Natl Acad Sci USA 104: 14917-14922, 2007.

123. Mao B, Zhao G, Lv X, Chen HZ, Xue Z, Yang B, Liu DP and Liang CC: Sirtl deacetylates c-Myc and promotes c-Myc/Max association. Int J Biochem Cell Biol 43: 1573-1581, 2011.

124. Bhadury J, Nilsson LM, Muralidharan SV, Green LC, Li Z, Gesner EM, Hansen HC, Keller UB, McLure KG and Nilsson JA: BET and HDAC inhibitors induce similar genes and biological effects and synergize to kill in Myc-induced murine lymphoma. Proc Natl Acad Sci USA 111: E2721-E2730, 2014

125. Nebbioso A, Carafa V, Conte M, Tambaro FP, Abbondanza C, Martens J, Nees M, Benedetti R, Pallavicini I, Minucci S, et al: c-Myc modulation and acetylation is a key HDAC inhibitor target in cancer. Clin Cancer Res 23: 2542-2555, 2017.

126. Wang F, Wang Z, Li D and Chen Q: Identification and characterization of a Bursaphelenchus xylophilus (Aphelenchida: Aphelenchoididae) Thermotolerance-related gene: Bx-HSP90. Int J Mol Sci 13: 8819-8833, 2012.

127. Kovacs JJ, Murphy PJ, Gaillard S, Zhao X, Wu JT, Nicchitta CV, Yoshida M, Toft DO, Pratt WB and Yao TP: HDAC6 regulates Hsp90 acetylation and chaperone-dependent activation of glucocorticoid receptor. Mol Cell 18: 601-607, 2005.

128. Scroggins BT, Robzyk K, Wang D, Marcu MG, Tsutsumi S, Beebe K, Cotter RJ, Felts S, Toft D, Karnitz L, et al: An acetylation site in the middle domain of Hsp90 regulates chaperone function. Mol Cell 25: 151-159, 2007.

129. Meng Q, Chen X, Sun L, Zhao C, Sui G and Cai L: Carbamazepine promotes Her-2 protein degradation in breast cancer cells by modulating HDAC6 activity and acetylation of Hsp90. Mol Cell Biochem 348: 165-171, 2011

130. Rahimi N and Costello CE: Emerging roles of post-translational modifications in signal transduction and angiogenesis. Proteomics 15: 300-309, 2015.

131. Yan MS, Turgeon PJ, Man HJ, Dubinsky MK, Ho JJD, El-Rass S, Wang YD, Wen XY and Marsden PA: Acetyltransferase 7 (KAT7)-dependent intragenic histone acetylation regulates endothelial Histone cell gene regulation. J Biol Chem 293: 4381-4402, 2018.

132. Alomer RM, da Silva EML, Chen J, Piekarz KM, McDonald K, Sansam CG, Sansam CL and Rankin S: Esco1 and Esco2 regulate distinct cohesin functions during cell cycle progression. Proc Natl Acad Sci USA 114: 9906-9911, 2017.

133. Rowland BD, Roig MB, Nishino T, Kurze A, Uluocak P, Mishra A, Beckouët F, Underwood P, Metson J, Imre R, et al: Building sister chromatid cohesion: Smc3 acetylation counteracts an antiestablishment activity. Mol Cell 33: 763-774, 2009.

134. Gallinari P, Di Marco S, Jones P, Pallaoro M and Steinkuhler C: HDACs, histone deacetylation and gene transcription: From molecular biology to cancer therapeutics. Cell Res 17: 195-211, 2007.

135. Schlesinger J, Schueler M, Grunert M, Fischer JJ, Zhang Q, Krueger T, Lange M, Tönjes M, Dunkel I and Sperling SR: The cardiac transcription network modulated by Gata4, Mef2a, Nkx2.5, Srf, histone modifications, and microRNAs. PLoS Genet 7: e1001313, 2011

136. Leszczynska KB, Foskolou IP, Abraham AG, Anbalagan S Tellier C, Haider S, Span PN, O'Neill EE, Buffa FM and Hammond EM: Hypoxia-induced p53 modulates both apoptosis and radiosensitivity via AKT. J Clin Invest 125: 2385-2398, 2015.

137. Vadvalkar SS, Matsuzaki S, Eyster CA, Giorgione JR, Bockus LB, Kinter CS, Kinter M and Humphries KM: Decreased mitochondrial pyruvate transport activity in the diabetic heart: Role of mitochondrial pyruvate carrier 2 (MPC2) Acetylation. J Biol Chem 292: 4423-4433, 2017.

138. Hu H, Zhu W, Qin J, Chen M, Gong L, Li L, Liu X, Tao Y, Yin H, Zhou H, et al: Acetylation of PGK1 promotes liver cancer cell proliferation and tumorigenesis. Hepatology 65: 515-528, 2017.

139. Wang Y, Wang F, Bao X and Fu L: Systematic analysis of lysine acetylome reveals potential functions of lysine acetylation in Shewanella baltica, the specific spoilage organism of aquatic products. J Proteomics 205: 103419, 2019. 
140. Chen J, Rong X, Fan G, Li S and Li Q: Effects of different concentrations of putrescine on proliferation, migration and apoptosis of human skin fibroblasts. Nan Fang Yi Ke Da Xue Xue Bao 35: 758-762, 2015 (In Chinese).

141. Mo R, Yang M, Chen Z, Cheng Z, Yi X, Li C, He C, Xiong Q, Chen H, Wang Q and Ge F: Acetylome analysis reveals the involvement of lysine acetylation in photosynthesis and carbon metabolism in the model cyanobacterium Synechocystis sp. PCC 6803. J Proteome Res 14: 1275-1286, 2015.

142. Yu BJ, Kim JA, Moon JH, Ryu SE and Pan JG: The diversity of lysine-acetylated proteins in Escherichia coli. J Microbiol Biotechnol 18: 1529-1536, 2008.

143. Savoia M, Cencioni C, Mori M, Atlante S, Zaccagnini G, Devanna P, Di Marcotullio L, Botta B, Martelli F, Zeiher AM, et al: $\mathrm{P} 300 / \mathrm{CBP}-a s s o c i a t e d$ factor regulates transcription and function of isocitrate dehydrogenase 2 during muscle differentiation. FASEB J 33: 4107-4123, 2019.

144. Baeza J, Smallegan MJ and Denu JM: Mechanisms and dynamics of protein acetylation in mitochondria. Trends Biochem Sci 41: 231-244, 2016.

145. Wagner GR and Hirschey MD: Nonenzymatic protein acylation as a carbon stress regulated by sirtuin deacylases. Mol Cell 54: $5-16,2014$

146. Ronowska A, Szutowicz A, Bielarczyk H, Gul-Hinc S, Klimaszewska-Łata J,Dyś A,Zyśk M and Jankowska-Kulawy A: The regulatory effects of Acetyl-CoA distribution in the healthy and diseased brain. Front Cell Neurosci 12: 169, 2018.

147. Zaini MA, Muller C, de Jong TV, Ackermann T, Hartleben G, Kortman G, Gührs KH, Fusetti F, Krämer OH, Guryev V and Calkhoven CF: A p300 and SIRT1 regulated acetylation switch of $\mathrm{C} / \mathrm{EBP} \alpha$ controls mitochondrial function. Cell Rep 22: 497-511, 2018

148. Priante G, Gianesello L, Ceol M, Del Prete D and Anglani F: Cell death in the kidney. Int J Mol Sci 20: 3598, 2019.

149. De Rasmo D, Signorile A, De Leo E, Polishchuk EV, Ferretta A Raso R, Russo S, Polishchuk R, Emma F and Bellomo F: Mitochondrial dynamics of proximal tubular epithelial cells in Nephropathic Cystinosis. Int J Mol Sci 21: 192, 2019.

150. Silva Junior G, Liborio AB, Mota RM, Abreu KLS, Silva AEB, Silva SMHA and Daher EF: Acute kidney injury in AIDS Frequency, RIFLE classification and outcome. Brazilian J Med Biol Res 43: 1102-1108, 2010.

151. Kellum JA, Sileanu FE, Murugan R, Lucko N, Shaw AD and Clermont G: Classifying AKI by urine output versus serum creatinine level. J Am Soc Nephrol 26: 2231-2238, 2015.

152. Cianciolo Cosentino C, Skrypnyk NI, Brilli LL, Chiba T, Novitskaya T, Woods C, West J, Korotchenko VN, McDermott L, Day BW, et al: Histone deacetylase inhibitor enhances recovery after AKI. J Am Soc Nephrol 24: 943-953, 2013.

153. Ranganathan P, Hamad R, Mohamed R, Jayakumar C, Muthusamy T and Ramesh G: Histone deacetylase-mediated silencing of AMWAP expression contributes to cisplatin nephrotoxicity. Kidney Int 89: 317-326, 2016.

154. Fan H, Yang HC, You L, Wang YY, He WJ and Hao CM: The histone deacetylase, SIRT1, contributes to the resistance of young mice to ischemia/reperfusion-induced acute kidney injury. Kidney Int 83: 404-413, 2013.

155. Xu S, Gao Y, Zhang Q, Wei S, Chen Z, Dai X, Zeng Z and Zhao KS: SIRT1/3 activation by resveratrol attenuates acute kidney injury in a septic rat model. Oxid Med Cell Longev 2016: 7296092,2016

156. Ozkok A, Ravichandran K, Wang Q, Ljubanovic D and Edelstein CL: NF- $\kappa \mathrm{B}$ transcriptional inhibition ameliorates cisplatin-induced acute kidney injury (AKI). Toxicol Lett 240: 105-113, 2016

157. Morigi M, Perico L, Rota C, Longaretti L, Conti S, Rottoli D, Novelli R, Remuzzi G and Benigni A: Sirtuin 3-dependent mitochondrial dynamic improvements protect against acute kidney injury. J Clin Invest 125: 715-726, 2015.

158. Zhang Q, Liu X, Li N, Zhang J, Yang J and Bu P: Sirtuin 3 deficiency aggravates contrast-induced acute kidney injury. J Transl Med 16: 313, 2018.

159. Ning YC, Cai GY, Zhuo L, Gao JJ, Dong D, Cui SY, Shi SZ, Feng Z, Zhang L, Sun XF and Chen XM: Beneficial effects of short-term calorie restriction against cisplatin-induced acute renal injury in aged rats. Nephron Exp Nephrol 124: 19-27, 2013.

160. Scharman EJ and Troutman WG: Prevention of kidney injury following rhabdomyolysis: A systematic review. Ann Pharmacother 47: 90-105, 2013.
161. Jian B, Yang S, Chaudry IH and Raju R: Resveratrol restores sirtuin 1 (SIRT1) activity and pyruvate dehydrogenase kinase 1 (PDK1) expression after hemorrhagic injury in a rat model. Mol Med 20: 10-16, 2014.

162. Si Y, Bao H, Han L, Chen L, Zeng L, Jing L, Xing Y and Geng Y: Dexmedetomidine attenuation of renal ischaemia-reperfusion injury requires sirtuin 3 activation. Br J Anaesth 121: 1260-1271, 2018.

163. Chaix MA, Andelfinger G and Khairy P: Genetic testing in congenital heart disease: A clinical approach. World J Cardiol 8: 180-191, 2016

164. Yuan S, Zaidi S and Brueckner M: Congenital heart disease: Emerging themes linking genetics and development. Curr Opin Genet Dev 23: 352-359, 2013.

165. Wu G, Nan C, Rollo JC, Huang X and Tian J: Sodium valproate-induced congenital cardiac abnormalities in mice are associated with the inhibition of histone deacetylase. J Biomed Sci 17: 16, 2010

166. Zhong L, Zhu J, Lv T, Chen G, Sun H, Yang X, Huang X and Tian J: Ethanol and its metabolites induce histone lysine 9 acetylation and an alteration of the expression of heart development-related genes in cardiac progenitor cells. Cardiovasc Toxicol 10: 268-274, 2010.

167. Li L, Zhu J, Tian J, Liu X and Feng C: A role for Gen5 in cardiomyocyte differentiation of rat mesenchymal stem cells. Mol Cell Biochem 345: 309-316, 2010.

168. Pillai VB, Sundaresan NR, Jeevanandam V and Gupta MP: Mitochondrial SIRT3 and heart disease. Cardiovasc Res 88: 250-256, 2010

169. Sundaresan NR, Samant SA, Pillai VB, Rajamohan SB and Gupta MP: SIRT3 is a stress-responsive deacetylase in cardiomyocytes that protects cells from stress-mediated cell death by deacetylation of Ku70. Mol Cell Biol 28: 6384-6401, 2008.

170. Zhang L, Wang H, Zhao Y, Wang J, Dubielecka PM, Zhuang S, Qin G, Chin YE, Kao RL and Zhao TC: Myocyte-specific overexpressing HDAC4 promotes myocardial ischemia/reperfusion injury. Mol Med 24: 37, 2018

171. Möller T and de Lange C: Myocardial fibrosis in congenital heart disease. Tidsskr Nor Laegeforen: 138: 2018 (In Norwegian) doi: 10.4045/tidsskr.18.0864.

172. Pang M and Zhuang S: Histone deacetylase: A potential therapeutic target for fibrotic disorders. J Pharmacol Exp Ther 335: 266-272, 2010.

173. Morimoto T, Sunagawa Y, Fujita M and Hasegawa K: Novel heart failure therapy targeting transcriptional pathway in cardiomyocytes by a natural compound, curcumin. Circ J 74: 1059-1066, 2010.

174. Hu M, Zhang Q, Tian XH, Wang JL, Niu YX and Li G: lncRNA CCAT1 is a biomarker for the proliferation and drug resistance of esophageal cancer via the miR-143/PLK1/BUBR1 axis. Mol Carcinog 58: 2207-2217, 2019.

175. Li J and Qi Y: Ginsenoside Rg3 inhibits cell growth, migration and invasion in Caco-2 cells by downregulation of lncRNA CCAT1. Exp Mol Pathol 106: 131-138, 2019.

176. Zhang E, Han L, Yin D, He X, Hong L, Si X, Qiu M, Xu T, De W, Xu L, et al: H3K27 acetylation activated-long non-coding RNA CCAT1 affects cell proliferation and migration by regulating SPRY4 and HOXB13 expression in esophageal squamous cell carcinoma. Nucleic Acids Res 45: 3086-3101, 2017.

177. Zhang H, Xie C, Yue J, Jiang Z, Zhou R, Xie R, Wang Y and Wu S: Cancer-associated fibroblasts mediated chemoresistance by a FOXO1/TGF $\beta 1$ signaling loop in esophageal squamous cell carcinoma. Mol Carcinog 56: 1150-1163, 2017.

178. Zhao Y, Yang J, Liao W, Liu X, Zhang H, Wang S, Wang D, Feng J, Yu L and Zhu WG: Cytosolic FoxO1 is essential for the induction of autophagy and tumour suppressor activity. Nat Cell Biol 12: 665-675, 2010.

179. Yu H, Ye W, Wu J, Meng X, Liu RY, Ying X, Zhou Y, Wang H, Pan $\mathrm{C}$ and Huang W: Overexpression of sirt7 exhibits oncogenic property and serves as a prognostic factor in colorectal cancer. Clin Cancer Res 20: 3434-3445, 2014.

180. Li D, Sun X, Zhang L, Yan B, Xie S, Liu R, Liu M and Zhou J: Histone deacetylase 6 and cytoplasmic linker protein 170 function together to regulate the motility of pancreatic cancer cells. Protein Cell 5: 214-223, 2014.

181. Sharma S and Taliyan R: Histone deacetylase inhibitors: Future therapeutics for insulin resistance and type 2 diabetes. Pharmacol Res 113: 320-326, 2016.

182. Berry JM, Cao DJ, Rothermel BA and Hill JA: Histone deacetylase inhibition in the treatment of heart disease. Expert Opin Drug Saf 7: 53-67, 2008. 
183. Yoon S, Kang G and Eom GH: HDAC Inhibitors: Therapeutic potential in fibrosis-associated human diseases. Int J Mol Sci 20: $1329,2019$.

184. Clawson GA: Histone deacetylase inhibitors as cancer therapeutics. Ann Transl Med 4: 287, 2016.

185. Peserico A and Simone C: Physical and functional HAT/HDAC interplay regulates protein acetylation balance. J Biomed Biotechnol 2011: 371832, 2011.

186. Qiu X, Xiao X, Li N and Li Y: Histone deacetylases inhibitors (HDACis) as novel therapeutic application in various clinical diseases. Prog Neuropsychopharmacol Biol Psychiatry 72: 60-72, 2017.

187. Xu W, Ngo L, Perez G, Dokmanovic M and Marks PA: Intrinsic apoptotic and thioredoxin pathways in human prostate cancer cell response to histone deacetylase inhibitor. Proc Natl Acad Sci USA 103: 15540-15545, 2006.

188. Rosato RR and Grant S: Histone deacetylase inhibitors: Insights into mechanisms of lethality. Expert Opin Ther Targets 9: 809-824, 2005.

189. Minucci S and Pelicci PG: Histone deacetylase inhibitors and the promise of epigenetic (and more) treatments for cancer. Nat Rev Cancer 6: 38-51, 2006.

190. Lane AA and Chabner BA: Histone deacetylase inhibitors in cancer therapy. J Clin Oncol 27: 5459-5468, 2009.

191. Eckschlager T, Plch J, Stiborova M and Hrabeta J: Histone deacetylase inhibitors as anticancer drugs. Int J Mol Sci 18 1414, 2017.

192. Di Pompo G, Salerno M, Rotili D, Valente S, Zwergel C, Avnet S, Lattanzi G, Baldini N and Mai A: Novel histone deacetylase inhibitors induce growth arrest, apoptosis, and differentiation in sarcoma cancer stem cells. J Med Chem 58: 4073-4079, 2015.

193. Debeb BG, Lacerda L, Larson R, Wolfe AR, Krishnamurthy S, Reuben JM, Ueno NT, Gilcrease M and Woodward WA: Histone deacetylase inhibitor-induced cancer stem cells exhibit high pentose phosphate pathway metabolism. Oncotarget 7: 28329-28339, 2016.

194. Cao D, Wang M, Qiu X, Liu D, Jiang H, Yang N and Xu RM: Structural basis for allosteric, substrate-dependent stimulation of SIRT1 activity by resveratrol. Genes Dev 29: 1316-1325, 2015

195. Li J, Chong T, Wang Z, Chen H, Li H, Cao J, Zhang P and $\mathrm{Li}$ H: A novel anticancer effect of resveratrol: Reversal of epithelial-mesenchymal transition in prostate cancer cells. Mol Med Rep 10: 1717-1724, 2014

196. Moussaieff A, Rouleau M, Kitsberg D, Cohen M, Levy G, Barasch D, Nemirovski A, Shen-Orr S, Laevsky I, Amit M, et al: Glycolysis-mediated changes in acetyl-CoA and histone acetylation control the early differentiation of embryonic stem cells. Cell Metab 21: 392-402, 2015

197. Hezroni H, Tzchori I, Davidi A, Mattout A, Biran A, Nissim-Rafinia M, Westphal H and Meshorer E: H3K9 histone acetylation predicts pluripotency and reprogramming capacity of ES cells. Nucleus 2: 300-309, 2011.

198. Zhang Y, Cui P, Li Y, Feng G, Tong M, Guo L, Li T, Liu L, Li W and Zhou Q: Mitochondrially produced ATP affects stem cell pluripotency via Actl6a-mediated histone acetylation. FASEB J 32: 1891-1902, 2018.

199. Qiao Y, Wang R, Yang X, Tang K and Jing N: Dual roles of histone H3 lysine 9 acetylation in human embryonic stem cell pluripotency and neural differentiation. J Biol Chem 290: 2508-2520, 2015

200. Jacobs KM, Misri S, Meyer B, Raj S, Zobel CL, Sleckman BP, Hallahan DE and Sharma GG: Unique epigenetic influence of $\mathrm{H} 2 \mathrm{AX}$ phosphorylation and $\mathrm{H} 3 \mathrm{~K} 56$ acetylation on normal stem cell radioresponses. Mol Biol Cell 27: 1332-1345, 2016

201. Wen Y, Yang H, Wu J, Wang A, Chen X, Hu S, Zhang Y, Bai D and Jin Z: COL4A2 in the tissue-specific extracellular matrix plays important role on osteogenic differentiation of periodontal ligament stem cells. Theranostics 9: 4265-4286, 2019.

202.Li B, Sun J, Dong Z, Xue P, He X, Liao L, Yuan L and Jin Y: GCN5 modulates osteogenic differentiation of periodontal ligament stem cells through DKK1 acetylation in inflammatory microenvironment. Sci Rep 6: 26542, 2016.
203. Liu N, Shi S, Deng M, Tang L, Zhang G, Liu N, Ding B, Liu W, Liu Y, Shi H, et al: High levels of $\beta$-catenin signaling reduce osteogenic differentiation of stem cells in inflammatory microenvironments through inhibition of the noncanonical Wnt pathway. J Bone Miner Res 26: 2082-2095, 2011.

204. Ishitani T, Kishida S, Hyodo-Miura J, Ueno N, Yasuda J, Waterman M, Shibuya H, Moon RT, Ninomiya-Tsuji J and Matsumoto K: The TAK1-NLK mitogen-activated protein kinase cascade functions in the Wnt-5a/Ca(2+) pathway to antagonize Wnt/beta-catenin signaling. Mol Cell Biol 23: 131-139, 2003.

205. Wang H, Diao D, Shi Z, Zhu X, Gao Y, Gao S, Liu X, Wu Y, Rudolph KL, Liu G, et al: SIRT6 controls hematopoietic stem cell homeostasis through epigenetic regulation of Wnt signaling. Cell Stem Cell 18: 495-507, 2016.

206. Wagner VP, Martins MD and Castilho RM: Histones acetylation and cancer stem cells (CSCs). Methods Mol Biol 1692: 179-193, 2018.

207. Liu C, Liu L, Shan J, Shen J, Xu Y, Zhang Q, Yang Z, Wu L, Xia F, Bie $P$, et al: Histone deacetylase 3 participates in self-renewal of liver cancer stem cells through histone modification. Cancer Lett 339: 60-69, 2013.

208. Liu D, Zhou P, Zhang L, Gong W, Huang G, Zheng Y and He F: HDAC1/DNMT3A-containing complex is associated with suppression of Oct 4 in cervical cancer cells. Biochemistry (Mosc) 77: 934-940, 2012

209. Choi HJ, Park JH, Park M, Won HY, Joo HS, Lee CH, Lee JY and Kong G: UTX inhibits EMT-induced breast CSC properties by epigenetic repression of EMT genes in cooperation with LSD1 and HDAC1. EMBO Rep 16: 1288-1298, 2015.

210. Salvador MA, Wicinski J, Cabaud O, Toiron Y, Finetti P, Josselin E, Lelièvre $\mathrm{H}$, Kraus-Berthier L, Depil S, Bertucci F, et al: The histone deacetylase inhibitor abexinostat induces cancer stem cells differentiation in breast cancer with low Xist expression. Clin Cancer Res 19: 6520-6531, 2013.

211. Corbin AS, Agarwal A, Loriaux M, Cortes J, Deininger MW and Druker BJ: Human chronic myeloid leukemia stem cells are insensitive to imatinib despite inhibition of BCR-ABL activity. J Clin Invest 121: 396-409, 2011.

212. Li L, Wang L, Li L, Wang Z, Ho Y, McDonald T, Holyoake TL, Chen $\mathrm{W}$ and Bhatia R: Activation of p53 by SIRT1 inhibition enhances elimination of CML leukemia stem cells in combination with imatinib. Cancer Cell 21: 266-281, 2012.

213. Hsu YC, Wu YT, Tsai CL and Wei YH: Current understanding and future perspectives of the roles of sirtuins in the reprogramming and differentiation of pluripotent stem cells. Exp Biol Med (Maywood) 243: 563-575, 2018.

214. Sun J, Wei HM, Xu J, Chang JF, Yang Z, Ren X, Lv WW, Liu LP, Pan LX, Wang X, et al: Histone H1-mediated epigenetic regulation controls germline stem cell self-renewal by modulating H4K16 acetylation. Nat Commun 6: 8856, 2015.

215. Hou T, Zheng G, Zhang P, Jia J, Li J, Xie L, Wei C and Li Y: LAceP: Lysine acetylation site prediction using logistic regression classifiers. PLoS One 9: e89575, 2014.

216. Chen $\mathrm{C}$, Huang $\mathrm{H}$ and $\mathrm{Wu} \mathrm{CH}$ : Protein bioinformatics databases and resources. Methods Mol Biol 1558: 3-39, 2017.

217. Wang L, Du Y, Lu M and Li T: ASEB: A web server for KAT-specific acetylation site prediction. Nucleic Acids Res 40: W376-379, 2012.

218. Deng W, Wang C, Zhang Y, Xu Y, Zhang S, Liu Z and Xue Y: GPS-PAIL: Prediction of lysine acetyltransferase-specific modification sites from protein sequences. Sci Rep 6: 39787, 2016.

219. Shi SP, Qiu JD, Sun XY, Suo SB, Huang SY and Liang RP: PLMLA: Prediction of lysine methylation and lysine acetylation by combining multiple features. Mol Biosyst 8: 1520-1527, 2012.

This work is licensed under a Creative Commons Attribution-NonCommercial-NoDerivatives 4.0 International (CC BY-NC-ND 4.0) License. 